\title{
Sustainable Land Management (SLM) Practices in Drylands: How Do They Address Desertification Threats?
}

\author{
G. Schwilch $\cdot$ H. P. Liniger $\cdot$ H. Hurni
}

Received: 12 April 2012/ Accepted: 3 May 2013/Published online: 24 May 2013

(c) Springer Science+Business Media New York 2013

\begin{abstract}
Managing land sustainably is a huge challenge, especially under harsh climatic conditions such as those found in drylands. The socio-economic situation can also pose challenges, as dryland regions are often characterized by remoteness, marginality, low-productive farming, weak institutions, and even conflict. With threats from climate change, disputes over water, competing claims on land, and migration increasing worldwide, the demands for sustainable land management (SLM) measures will only increase in the future. Within the EU-funded DESIRE project, researchers and stakeholders jointly identified existing SLM technologies and approaches in 17 dryland study sites located in the Mediterranean and around the world. In order to evaluate and share this valuable SLM experience, local researchers documented the SLM technologies and approaches in collaboration with land users, utilizing the internationally recognized WOCAT questionnaires. This article provides an analysis of 30 technologies and 8 approaches, enabling an initial evaluation of how SLM addresses prevalent dryland threats, such as water scarcity, soil degradation, vegetation degradation and low production, climate change, resource use conflicts, and migration. Among the impacts attributed to the documented technologies, those mentioned most were diversified and enhanced production and better management of water and soil degradation, whether through water harvesting, improving soil moisture, or reducing runoff. Favorable local-scale cost-
\end{abstract}

G. Schwilch $(\varangle) \cdot$ H. P. Liniger

Centre for Development and Environment (CDE), University of Bern, Hallerstrasse 10, 3012 Bern, Switzerland

e-mail: gudrun.schwilch@cde.unibe.ch

H. Hurni

Institute of Geography, University of Bern, Hallerstrasse 12,

3012 Bern, Switzerland benefit relationships were mainly found when considered over the long term. Nevertheless, SLM was found to improve people's livelihoods and prevent further outmigration. More field research is needed to reinforce expert assessments of SLM impacts and provide the necessary evidence-based rationale for investing in SLM.

Keywords Sustainable land management .

Desertification - Impact assessment · Cost-benefit

\section{Introduction}

Managing land sustainably is a huge challenge for land users and other stakeholders around the world. In drylands, characterized by harsh climatic conditions and water scarcity, it is especially difficult to reap benefits from land without degrading resources. Disturbance of dryland ecosystems can quickly lead to severe land degradation and thus desertification. Desertification is defined as "land degradation in arid, semi-arid, and dry subhumid areas resulting from various factors, including climatic fluctuations and human activities" (UNCCD 2008). It is a vicious cycle in which aridity, land degradation, climate change, and biodiversity loss are strongly interlinked (Cowie and others 2011). On average, populations living in drylands lag far behind the rest of the world in terms of human wellbeing and development indicators (MA 2005).

Combating desertification is complex and usually requires changing the very land management that contributed to desertification in the first place (WWAP 2012). In recent years, the term and the concept of sustainable land management (SLM) has growingly been acknowledged and widely promoted as a response to land degradation and desertification. It entails measures of land and water 
conservation that support land-based production and ecosystems for current and future generations. SLM's key principles are the productivity and protection of natural resources, coupled with economic viability, and social acceptability. In drylands in particular, it is very difficult to increase agricultural productivity on existing land under existing conditions- to meet growing demand for foodmuch less to begin to devise ways of offsetting future yield losses due to climate change (Hurni and others 2008; Wegner and Zwart 2011). Key threats in drylands-and thus challenges for SLM in drylands-include low productivity, water stress, climate variability and change, high risks of natural disasters and hazards, marginality and remoteness, migration, and population pressure.

While many SLM practices exist and are applied by land users, the upscaling of such practices remains insufficient. Based on various studies (Sietz and others 2011; Bossio and others 2010), it appears feasible to learn from local SLM experiences and transfer intervention options between similar socio-ecological systems - though drylands display very diverse characteristics (Sietz and others 2011). Especially in areas where the risks of production failure and land degradation are high, such as in drylands, it is easier to build on the experience of farmer innovatorsboth for new and existing technologies-than to introduce completely new interventions (Thomas 2008; Critchley and others 1999).

Within the EU-funded DESIRE project, ${ }^{1}$ a range of desertification mitigation strategies were documented and evaluated in 17 dryland study sites located in the Mediterranean region and around the world. Researchers and stakeholders jointly identified existing SLM technologies and approaches used by local land users, collaboratively documenting them with the help of the internationally recognized and standardized WOCAT $^{2}$ questionnaires (WOCAT 2008a, b) in order to evaluate and share their experience. This documentation process formed an integral part of a broader multi-step process consisting of: identifying SLM solutions in a first stakeholder workshop (Schwilch and others 2009); documenting existing experiences with SLM (the data source for the present analyses); selecting the most promising option in a second stakeholder workshop using a decision support tool (Schwilch and others 2012a); and finally testing implementation in the field (Jetten 2013). These steps are embedded in the overall DESIRE framework (Hessel and others 2013). When applied in combination and in sequence, the steps contribute

\footnotetext{
1 Desertification Mitigation and Remediation of Land; 2007-2012; http://www.desire-project.eu.

2 World Overview of Conservation Approaches and Technologies; http://www.wocat.net.
}

to multi-stakeholder learning for SLM (Schwilch and others 2012b).

Following a brief description of the WOCAT methodology and the DESIRE setup/procedure, this article presents the results of analyzing documentation on existing SLM identified in stakeholder workshops at the 17 DESIRE study sites. By grouping the identified SLM technologies/approaches and collating experts' and stakeholders' assessments of their effectiveness, an attempt is made (1) to identify common issues and threats encountered or addressed by SLM in drylands, and (2) to provide an initial indication of which documented SLM technologies and approaches show promise in dryland contexts and why. This first-ever attempt to scientifically analyze a set of WOCAT case studies includes a discussion of its limitations and drawbacks. While the documentation cannot be considered wholly as a representative of SLM in drylands, it is nevertheless valuable due to the number of dryland sites included, the number of stakeholders involved, and the breadth of information.

\section{Methodology and Analysis}

WOCAT emerged in the early 1990s from the conviction that more was being done to care for land than the general received wisdom on land degradation would suggest. Soil and water conservation (SWC) specialists from all over the world began building a network and recording good land management practices. Later, the focus on SWC was broadened to arrive at the more holistic concept of SLM. SLM can be defined as the use of land resourcesincluding soils, water, animals, and plants-to produce goods that meet changing human needs, while simultaneously ensuring the long-term productive potential of these resources and the maintenance of their environmental functions (WOCAT 2007).

The basic concepts behind the WOCAT methodology at the local level (Schwilch and others 2011) are listed below.

- Providing a standardized framework that enables comparison and sharing.

- Integrating socio-economic and bio-physical aspects.

- Using the knowledge of both specialists and land users as data sources, reinforced by quantitative and scientific data wherever possible.

- Using the same tools for both (self-)evaluation and for knowledge sharing.

WOCAT defines an SLM technology as an agronomic, vegetative, structural, or management measure applied in the field. An SLM approach is defined as the ways and means used to promote and implement a given SLM technology, whether through a project, an indigenous 
system, or a local initiative. Two separate WOCAT questionnaires are used to record SLM technologies and SLM approaches (WOCAT 2008a, b). Both questionnaires are divided into three parts, covering general information, specifications, and analysis.

The resulting data from the questionnaires are entered into an online database that is freely accessible to the public. $^{3}$ Predefined output formats enable viewing and printing the compiled information in a user-friendly format that supports knowledge exchange and compilation of inventories. Building on earlier WOCAT work (WOCAT 2007), an overview book has already been produced for the DESIRE project (Schwilch and others 2012c). The data published in that book provide the data basis for this article. This article represents the first scientific evaluation of a set of WOCAT-documented SLM technologies and approaches.

According to previous assessments of technologies documented using the WOCAT questionnaires, SLM must be based on the principles of improved water, soil fertility, plant management, and enhanced microclimates in order to increase land productivity (WOCAT 2007; Liniger and others 2011). The DESIRE case studies provided an opportunity to test these principles in dryland contexts.

The DESIRE project encompassed 17 dryland study sites distributed between 13 countries. The study sites were mainly located in Mediterranean countries (Portugal, Spain, Italy, Greece, Turkey, Tunisia, Morocco), but a few were more broadly distributed (Russia, China, Botswana, Cape Verde, Mexico, Chile). Sites were chosen based on the various desertification processes they presented. The aim was to include examples of key desertification processes, namely soil erosion by water and wind, salinization, vegetation degradation, competition for water, wildfires, and droughts. The different socio-economic and bio-physical contexts enabled DESIRE to work in a truly global "laboratory." Though the included sites cannot be considered representative of all dryland areas, they offer special insight into a broad range of dryland contexts. The simultaneous work in such a large set of study sites distinguishes this project from other efforts to examine SLM in drylands.

At each site, local SLM technologies and approaches were identified and selected within a standardized multistep process in collaboration with a variety of stakeholders (Schwilch and others 2009, 2012a). Stakeholder workshops were a key component of the DESIRE process and brought together relevant experts and (local) stakeholders. The

\footnotetext{
3 http://www.wocat.net/en/knowledge-base/technologiesapproaches. html.
}

workshop participants included land users, representatives of local authorities and community-based organizations, and external researchers and experts from NGOs and GOs. Between and after the workshops, the technologies and approaches identified were documented by teams of two to three experts in consultation with land users and other local stakeholders. A total of 85 experts participated in documenting and assessing existing SLM technologies and approaches in use at the DESIRE dryland study sites.

More than 40 SLM technologies and 20 SLM approaches were initially documented by the teams at the study sites. The selection was eventually narrowed to 30 technologies and 8 approaches that showed the most promise in the specific dryland contexts, based on the estimates of participating experts and stakeholders. In addition, the final selection was chosen to reflect a wide variety of SLM strategies, study sites, land use types, and degradation types. Taken together, the 30 technology case studies analyzed in this article encompass $3,000 \mathrm{~km}^{2}$ of dryland.

Most performance indicators-for example, the impact of a given SLM technology on degradation and its economic, ecological, and socio-cultural benefits or disadvantages-were assessed qualitatively by participants according to predefined response categories (such as "no/ negligible" for 0-5\%, "little" for 5-20\%, "medium" for $20-50 \%$, and "high" for $>50 \%$ of change). Where available, quantitative data were included.

The documentation of these technologies and approaches was eventually reviewed and controlled for quality by SLM experts from within the DESIRE consortium. During quality control, missing information was added and ambiguities or contradictions were cleared up iteratively together with the case study authors.

For the purpose of the present analyses and comparisons, the 30 documented SLM technologies were divided into 5 groups, which are detailed in Table 1. The groups are

- Cropping management

- Water management

- Cross-slope barriers

- Grazing land management

- Forest management

The groups were created based on common SLM categories, already familiar to most SLM specialists, and shared mechanisms of addressing degradation (e.g., agronomic measures for cropping management, management measures for grazing land technologies, and structural measures for water management). Two of the SLM technology groups-cross-slope barriers and forest management-consist of various measures, including technologies which combine two or more measures into one. An 


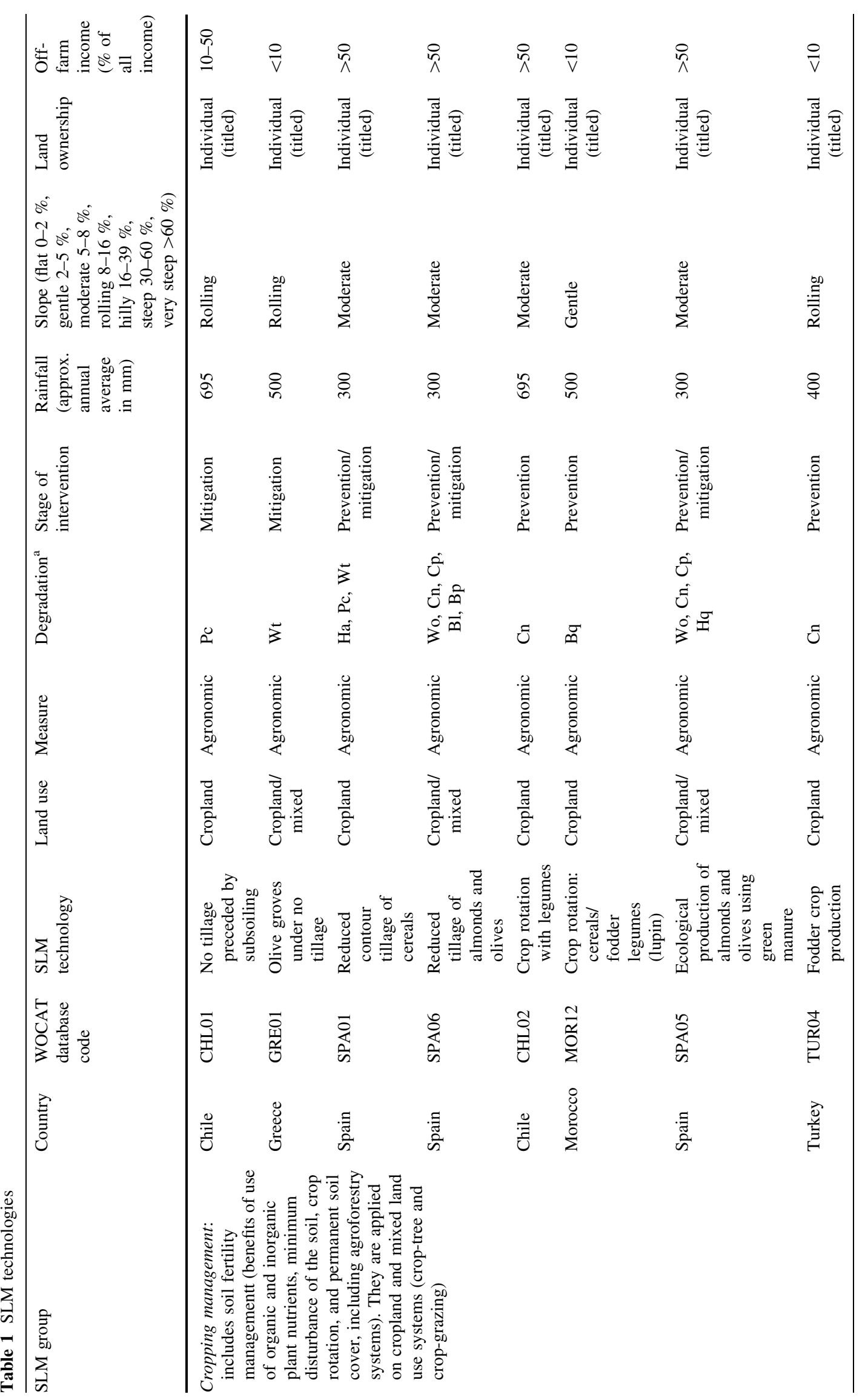




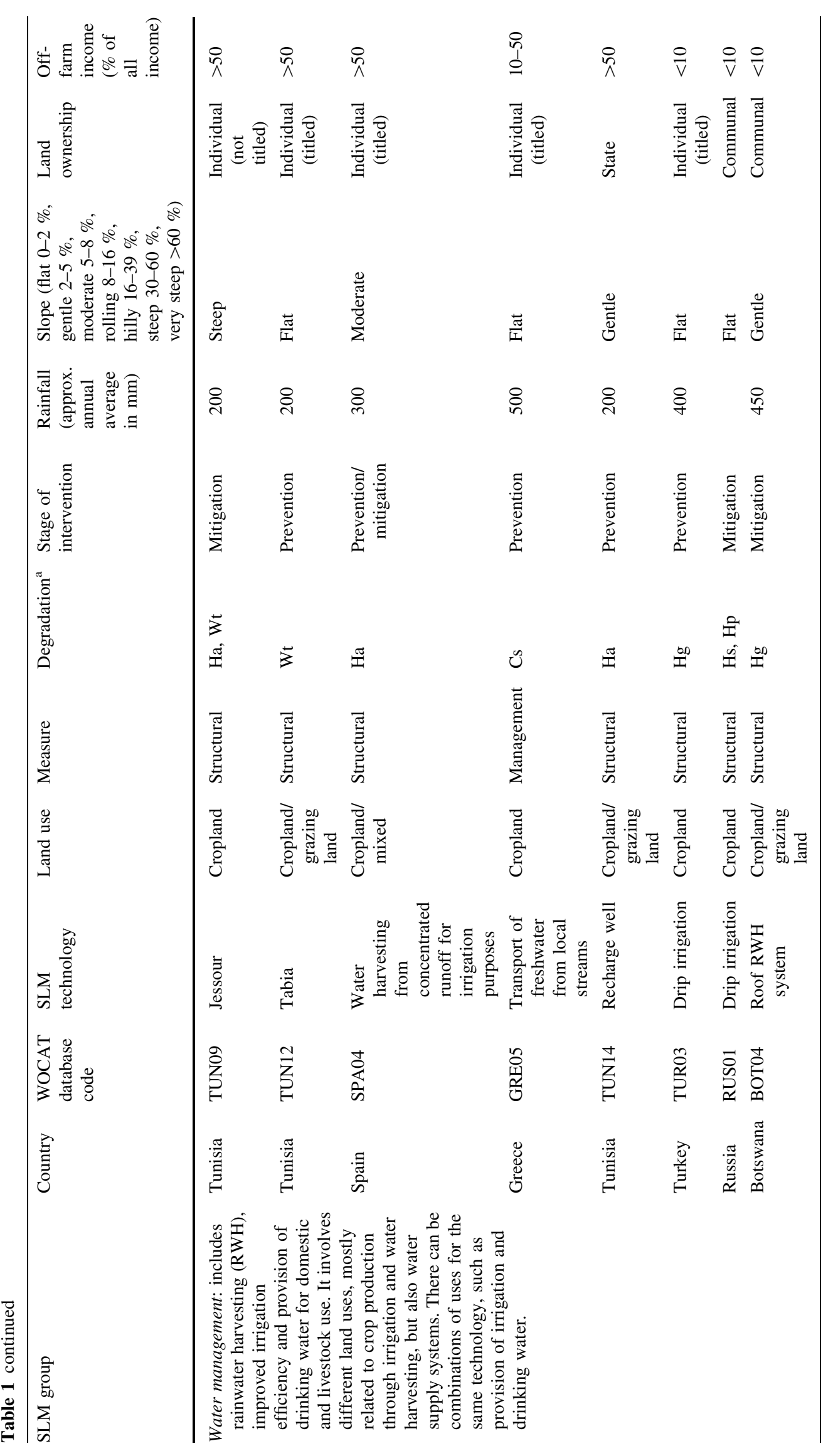




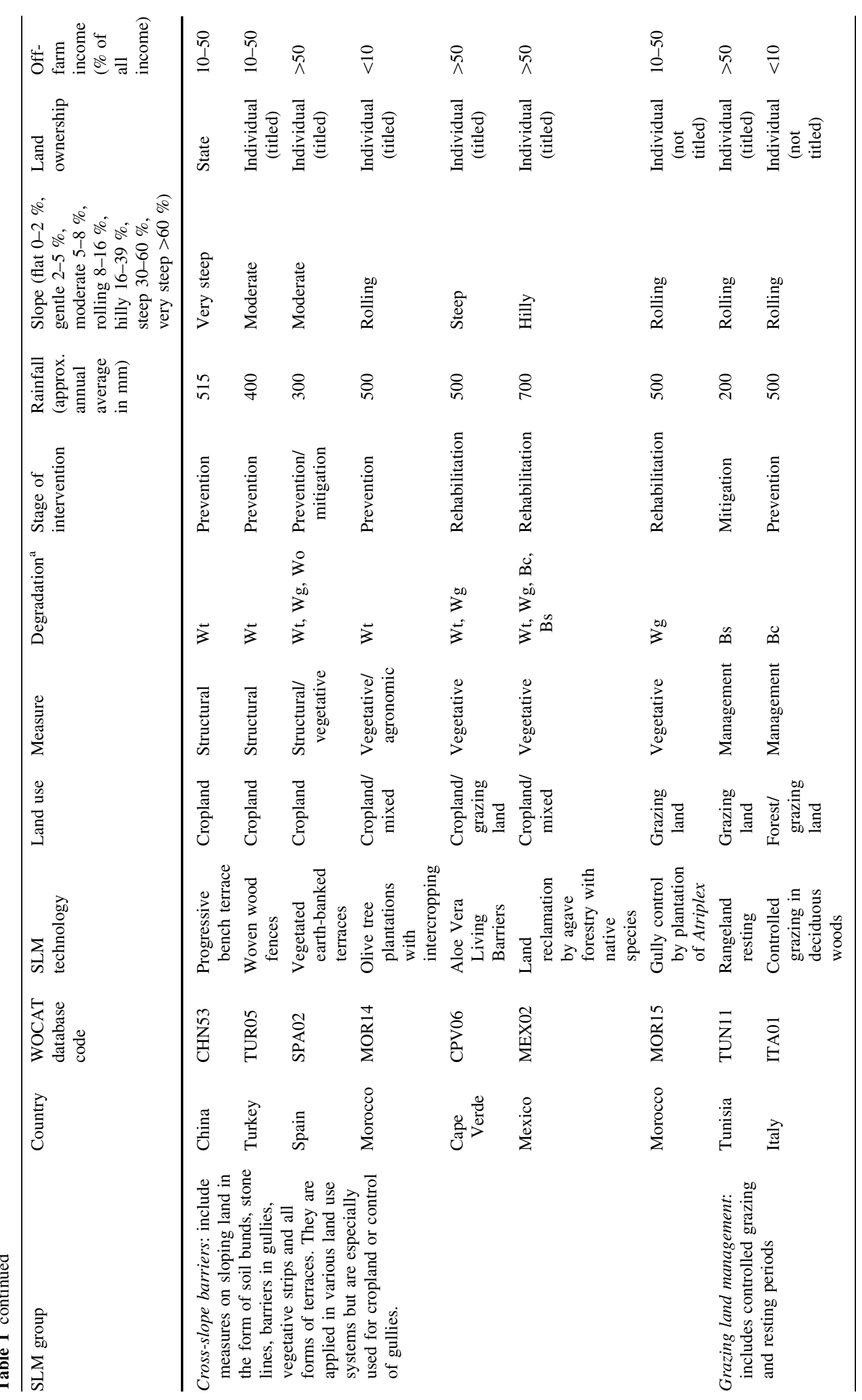




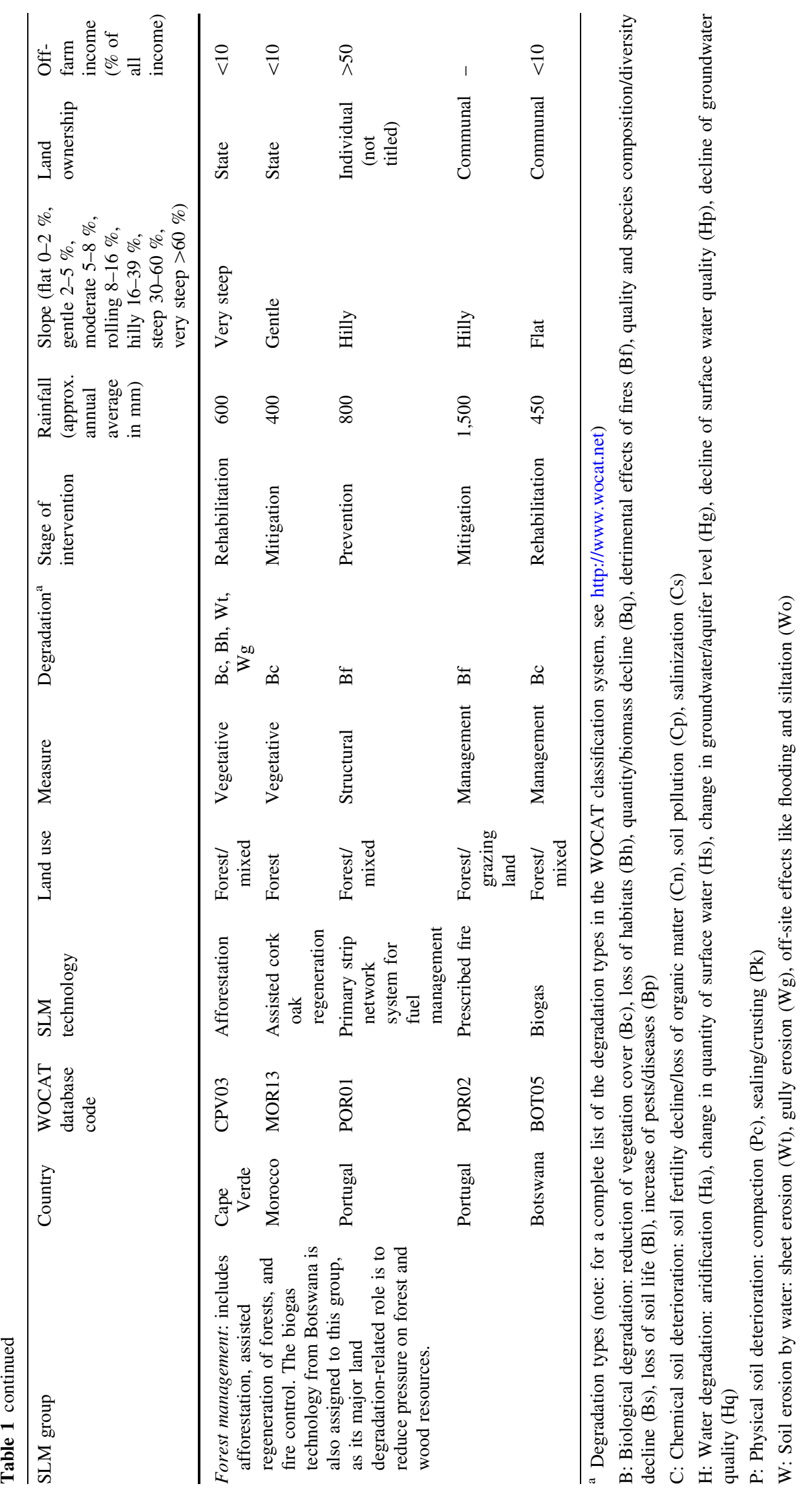


example of a typical combination is the "earth-banked terrace" from Spain, which is applied together with a vegetative measure-drought-resistant shrubs with good surface cover-to stabilize the structure.

On the basis of these five groups, aspects such as impacts, costs, and community involvement were comparatively analyzed and graphically displayed in charts. Participants' structured estimates of impacts ("no", "little", "medium", "high") were collated and converted into graphs to ease comparison. Though strict statistical comparisons and analyses were not possible-e.g., because the sample size was too small-the collated documentation and structured comparisons provide insights into key common issues and differences encountered in a relatively large number of dryland SLM case studies. In a comparative case study analysis, delving into the rich details of individual cases can constrain the generalizability of conclusions drawn (Srinivasan and others 2012). In this study, however, this constraint was somewhat mitigated by the structured gathering of data using the standardized WOCAT questionnaires. The results discussed below stem from analyses to determine whether and how the documented SLM technologies/approaches address key threats in drylands by means of improved water management, reduced soil degradation, diversified and enhanced production, resilience toward climate change and variability, and by providing socio-cultural benefits including conflict mitigation and prevention of outmigration.

\section{Results and Discussion}

\section{Characterization of SLM Technologies and Approaches} in Drylands

Out of the 30 technologies documented, 18 are applied on cropland, accounting for about $50 \%\left(1,500 \mathrm{~km}^{2}\right)$ of the area covered by the combined selection of case studies. Only three of the documented cropland technologies depend on irrigation water-the rest are rainfed. Though a majority of dryland areas are used as grazing land-where desertification problems are widespread and severegrazing land areas are typically neglected by researchers and development projects. This is due to the issues of unclear ownership, access rights, and governmental policies that discourage investments in rangelands (Thomas 2008). This observation was confirmed by the DESIRE case studies: only two of the documented SLM technologies are being applied solely on grazing land.

For illustration, some of the most prominent SLM groups are further described in Boxes 1, 2, 3, and 4.

Examination of the natural and human environment in which the technologies are applied highlights the unfavorable conditions that are typical of dryland areas. Soil depth is usually shallow, while topsoil organic matter and soil fertility are low. Such is the reality of drylands, where soils are generally less fertile due to less weathering, unfavorable substrates, and the reduced level of biological activity characteristic of arid and semi-arid climates. The extent to which degradation and nutrient mining may have contributed to reduced soil fertility was not assessed. Half of the technologies are applied on slopes greater than $8 \%$, where erosion and water loss are the main degradation problems that must be tackled. Other degradation typessuch as fertility depletion, vegetation degradation, or salinization-prevail on gently sloping or flat terrain, where cropping management and water management technologies are mainly applied. Surprisingly, soil crusting and sealing, a phenomenon often observed in drylands, was only mentioned in one technology description, belonging to Spain (reduced contour tillage technology). Finally, though wind erosion was reported at four study sites, none of the documented technologies specifically addresses degradation stemming from wind erosion; this may either be because no promising SLM options have been found for mitigating wind erosion in these areas, or because wind erosion is not considered the most serious degradation threat.

In the DESIRE study sites, the SLM technologies documented are mainly applied by land users with small-scale land holdings (57\%) who have wealth levels ranging from medium to poor and may be considered representative of average land users within their area. Remoteness and marginality played less of a role at the DESIRE study sites than might be expected, as most sites had relatively good access to various services and infrastructure (e.g., roads). Though people's access to off-farm employment was stated to be low in most cases, land users reportedly depended on off-farm activities for more than $50 \%$ of their income in about half of the cases documented. The rate of off-farm employment would likely be higher if access to such employment was greater. Outmigration played a role at many of the sites (e.g., Portugal, Spain, Tunisia, Morocco, Chile, Russia). In six of the study sites, outmigration was perceived to be constraining SLM by participants of the first stakeholder workshops (Schwilch and others 2009). It was seen as aggravating the situation rather than reducing pressure on resources, as is often assumed. During the second stakeholder workshops, participants cited the capacity to reduce outmigration as an important criterion when selecting SLM technologies, as aging of the rural population was considered as a major problem (Schwilch and others 2012a). When people migrate away from rural areas, key sources of labor vanish, land management is neglected, and local knowledge of traditional practices gradually diminishes and disappears, as seen in Spain regarding traditional water harvesting practices. While 
Box 1 Rainwater harvesting (RWH)

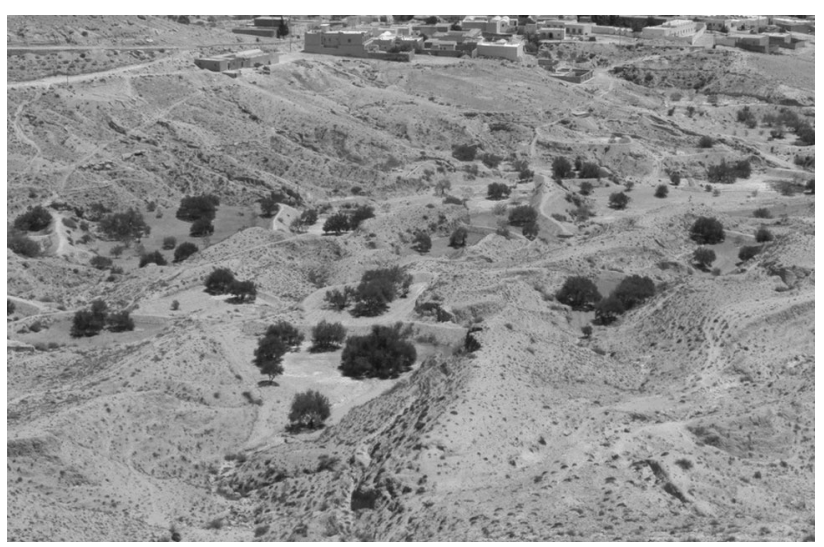

A myriad of RWH technologies exist worldwide—especially in drylands (Biazin and others 2012)—and the sample presented here only covers a few. The Botswana case study features a roof RWH system that mainly benefits the local drinking water supply. The case study in Spain and two in Tunisia feature runoff-harvesting systems that collect water from an upstream catchment area and directly divert it to cropping fields. In that way, the traditional water harvesting structure in Spain considerably increases the $300 \mathrm{~mm}$ of annual rainfall by an additional $550 \mathrm{~mm}$. The recharge well example in Tunisia catches and feeds floodwater into the aquifer. Not represented are in-field/in situ systems, consisting of small structural measures such as holes, pits, bunds, or small basins, constructed for the collection of on-site runoff within the field. (Photo: The ancient runoff water harvesting technique "Jessour" in Southern Tunisia; by C. Hauser)

Box 2 Crop rotation with (fodder) legumes

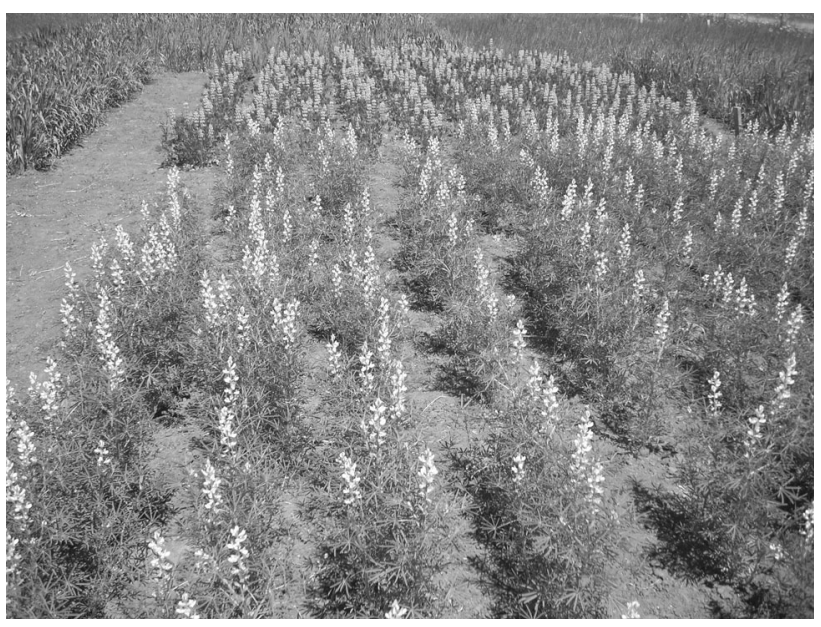

Examples of legume cropping are applied in crop rotation systems in Chile, Morocco, and Turkey, and—as green manure under tree cropsin Spain. While all four examples share the major aim of enhancing soil fertility, their economic purpose varies depending on the prevailing production system. In Spain, the legumes are not harvested but rather completely plowed under in order to fertilize the soil used for olive and almond production. In Chile, peas are used as vegetables, and lupines and vetch are used as fodder. In Turkey and Morocco, all legumes are used as a fodder crop for land users' animals. Haymaking is practiced in the Turkish study site. Especially in integrated cropping and livestock management production systems, as are often found in drylands, crop rotation with fodder legumes has a number of specific benefits. Leguminous crops improve fodder production, as they can be eaten by ruminants either as green fodder or as grain. Their nitrogenfixation capabilities benefit the next cultivation cycle, while simultaneously improving soil organic matter and soil structure. Soil cover is also considerably enhanced, as these crops often replace a non-vegetated (or even plowed) fallow period. Due to their invasiveness and extensive root system, legumes are able to grow on poor and stony soils and do not require much water. The leguminous nitrogen-fixating species used include vetch (Vicia sativa, Vicia atropurpurea), sainfoin (Onobrychis), white lupin (lupines albus), narrow-leaf lupin (Lupinus angustifolium and Wonga, an early flowering and high-yielding variety), yellow lupin (Lupinus luteus), peas (Pisum sativum), rocket, and alfalfa. The leguminous plants are often mixed with fodder crops such as maize, oat, wheat, barley, triticale, and fodder beet. Some of their benefits only appear over the long term, such as improved soil structure or organic matter. (Photo: Lupins forming part of the crop sequence in Mediterranean Chile; by S. Espinoza) 
Box 3 Reduced- or no-tillage technologies

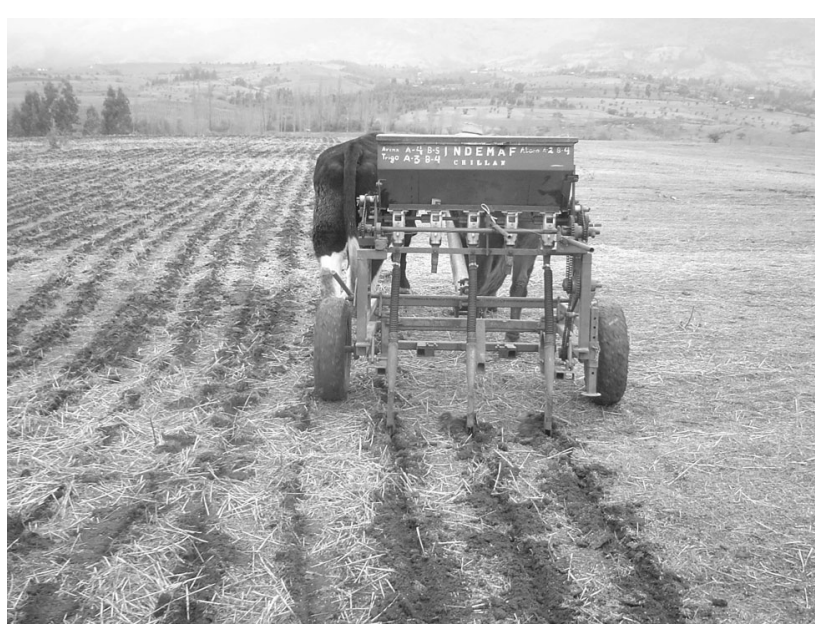

Changes in traditional plowing practices to reduced- or no-tillage practices were reported in Chile, Spain, and Greece. Two examples relate to cereal production and two are applied under olive and almond orchards. These practices mostly follow two principles of conservation agriculture, namely minimum disturbance of the soil and permanent cover (Liniger and others 2011). The main advantages are on-site conservation of rainwater by reducing surface runoff and evaporation loss $(>50 \%)$, reducing soil erosion $(>50 \%)$, fewer tillage operations, and reduced costs. The main difficulties to overcome are: (a) weed control through permanent cover, cutting of weeds, and chemical control; (b) possible compaction of the subsoil during the initial period of transition from plowing to no-tillage; (c) competition for plant residues being used for animal feed; and (d) the costs of new equipment (machinery), even though the maintenance costs are less than with conventional tillage. While water is conserved through reduced runoff and direct evaporation loss, additional water is consumed by the green cover. As a result, the yields of olives and almonds are not increased, but the environment is protected and costs are reduced. Practices of reduced tillage with permanent cover bear great potential in the Mediterranean region due to the large areas under olive and almond plantations there, which are prone to erosion under conventional tillage practices. (Photo: No-tillage agriculture in the Cauquenes Region, Chile; by C. Ruiz)

Box 4 Cross-slope barriers

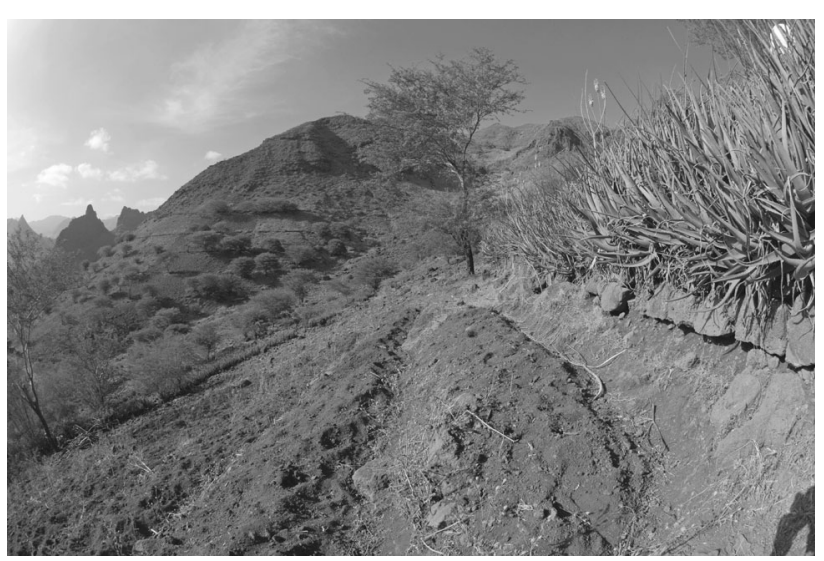

Two major types are represented in DESIRE: one with contour strips of wooden or vegetative barriers of aloe vera, agave, olives, and Atriplex, and the other consisting of terraces. Contour strips are mainly applied on moderately steep to steep slopes and have two main purposes: (a) reducing surface runoff and soil erosion, and thus soil fertility loss and downstream damages; and (b) accumulating water and nutrients within and above the strips for trees and crops. High establishment and maintenance costs are rewarded when barriers are reinforced with highly productive trees and shrubs. Both terrace examples are used for tree crops (olives in Spain and apples in China). The Loess plateau terraces are built up progressively by expanding the terraced area around the apple trees over a period of 5-10 years, while the terraces in Spain are constructed right from the beginning and reinforced with shrubs and grasses. (Photo: Aloe vera living barriers on Santiago Island, Cape Verde; by H. P. Liniger) 
remittances are one potentially positive consequence of migration, remittances were not mentioned at any of the DESIRE sites.

Eight SLM approaches were documented to illustrate implementation of the technologies in the field (see Table 2). The approaches ranged from projects for testing and disseminating new technologies to training and awareness-raising campaigns, rural development programs, and government programs of forest regulation. In most case studies, control of degradation and desertification was cited as the main objective of the documented approach. Other key objectives mentioned were enhancement of productivity and intensification of production. Finally, improvement of farmers' livelihoods-mainly through increased income-was named as a goal in connection with almost every approach.

The success of an approach in promoting and implementing SLM technologies often depends on the extent to which land users' underlying motivations are addressed. Among the approaches documented, land users were mainly motivated by the benefits of increased production, profitability, and/or payments and subsidies received (see Fig. 1). Land users in the two approaches documented from Western Europe-Spain and Portugal-were mainly motivated by rules and regulations (fines) or enforcement; this was not the case anywhere else. Apparently, these land users see little benefit to the SLM technologies other than EU compliance, casting doubt on their long-term use. Esthetic and environmental consciousness generally appeared to play a minor role in terms of people's motivations.

Impacts of SLM Technologies with Regard to Dryland Threats

\section{Improved Water Management}

According to the authors of the case studies (see Fig. 2), at least half of the technologies demonstrated the following ecological impacts: "increased soil moisture," "reduced surface runoff," "improved soil cover," and "reduced soil loss."

Water availability is the most common factor limiting (food) production in drylands. It is characterized by a mixture of scarcity, extreme variability, long dry seasons, recurrent dry spells and droughts, and occasional floods. Thus, improving water use efficiency to minimize water losses is of the utmost importance (Biazin and others 2012). The concept of green water use efficiency (GWUE) helps to
Table 2 SLM approaches

\begin{tabular}{|c|c|c|c|}
\hline Country & $\begin{array}{l}\text { SLM approach } \\
\text { name }\end{array}$ & Description & $\begin{array}{l}\text { WOCAT } \\
\text { database } \\
\text { code }\end{array}$ \\
\hline Spain & $\begin{array}{l}\text { Regional rural } \\
\text { development } \\
\text { program }\end{array}$ & $\begin{array}{l}\text { Regional development } \\
\text { program to protect } \\
\text { natural resources } \\
\text { and stimulate rural } \\
\text { economies }\end{array}$ & SPA01 \\
\hline Portugal & $\begin{array}{l}\text { Forest Intervention } \\
\text { Area (ZIF) }\end{array}$ & $\begin{array}{l}\text { ZIF assembles and } \\
\text { organizes small } \\
\text { forest holders and } \\
\text { defines a joint } \\
\text { intervention for } \\
\text { forest management } \\
\text { and protection }\end{array}$ & POR01 \\
\hline Russia & $\begin{array}{l}\text { Concerted thinking } \\
\text { on common } \\
\text { problems of water } \\
\text { scarcity }\end{array}$ & $\begin{array}{l}\text { Testing and } \\
\text { disseminating a } \\
\text { water saving } \\
\text { technology such as } \\
\text { drip irrigation }\end{array}$ & RUS01 \\
\hline Morocco & $\begin{array}{l}\text { Development of } \\
\text { rainfed agriculture }\end{array}$ & $\begin{array}{l}\text { Development of } \\
\text { unfavorable zones } \\
\text { by integrating all } \\
\text { components which } \\
\text { can enhance the } \\
\text { production, increase } \\
\text { incomes, and } \\
\text { provide sustainable } \\
\text { natural resource } \\
\text { management }\end{array}$ & MOR14 \\
\hline Tunisia & $\begin{array}{l}\text { Dryland watershed } \\
\text { management } \\
\text { approach }\end{array}$ & $\begin{array}{l}\text { Integrated land and } \\
\text { water management } \\
\text { approach, including } \\
\text { vegetative, } \\
\text { management, and } \\
\text { agronomic measures }\end{array}$ & TUN09 \\
\hline $\begin{array}{l}\text { Cape } \\
\text { Verde }\end{array}$ & $\begin{array}{l}\text { Training, } \\
\text { information, and } \\
\text { awareness raising }\end{array}$ & $\begin{array}{l}\text { Integration of } \\
\text { stakeholders in the } \\
\text { implementation of } \\
\text { natural resource } \\
\text { conservation } \\
\text { activities }\end{array}$ & CPV01 \\
\hline Mexico & $\begin{array}{l}\text { Participative actions } \\
\text { for economic } \\
\text { benefits of agave } \\
\text { forestry }\end{array}$ & $\begin{array}{l}\text { Land reclamation with } \\
\text { local agave (to } \\
\text { produce Mezcal) } \\
\text { associated with } \\
\text { trees, shrubs, and } \\
\text { grasses planted } \\
\text { through participative } \\
\text { actions for economic } \\
\text { benefit }\end{array}$ & MEX02 \\
\hline Chile & $\begin{array}{l}\text { Dissemination of soil } \\
\text { conservation } \\
\text { technologies in } \\
\text { dryland areas }\end{array}$ & $\begin{array}{l}\text { Dissemination of no } \\
\text { tillage with } \\
\text { subsoiling in the } \\
\text { Municipality of } \\
\text { Yumbel }\end{array}$ & CHL02 \\
\hline
\end{tabular}


Fig. 1 Main motivation of land users to implement SLM

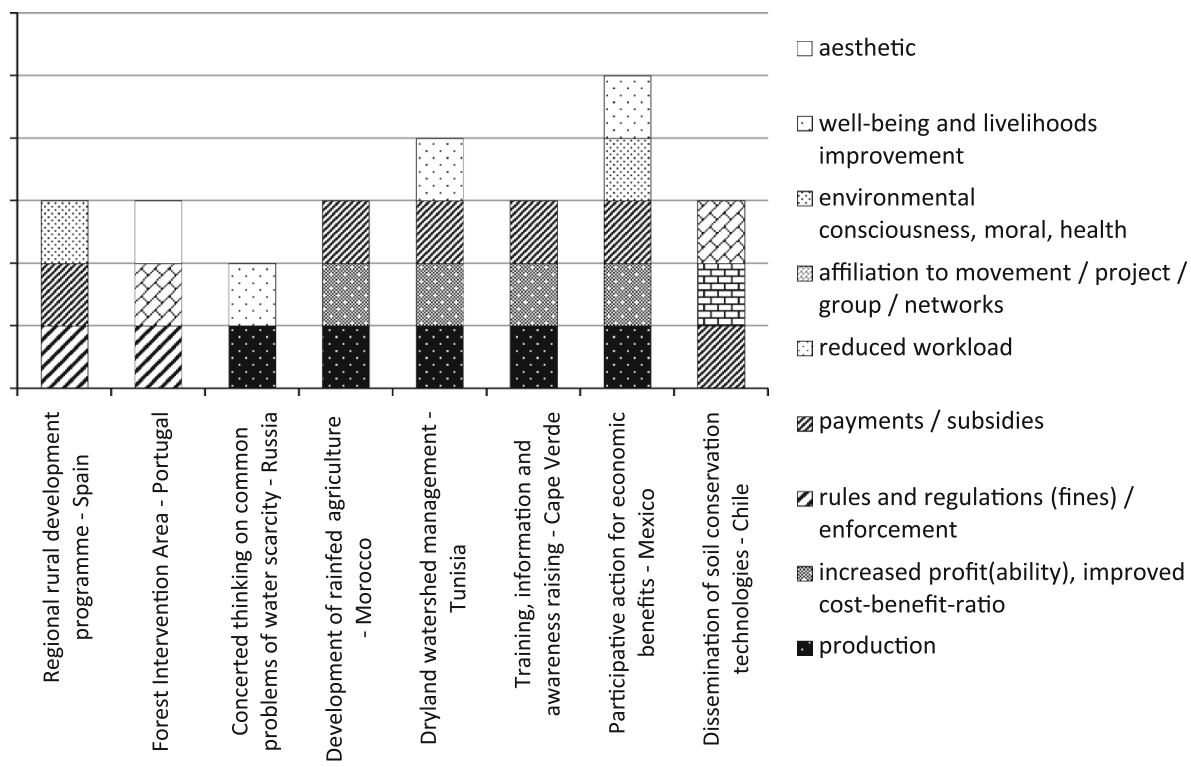

Fig. 2 Ecological impacts of the SLM technologies

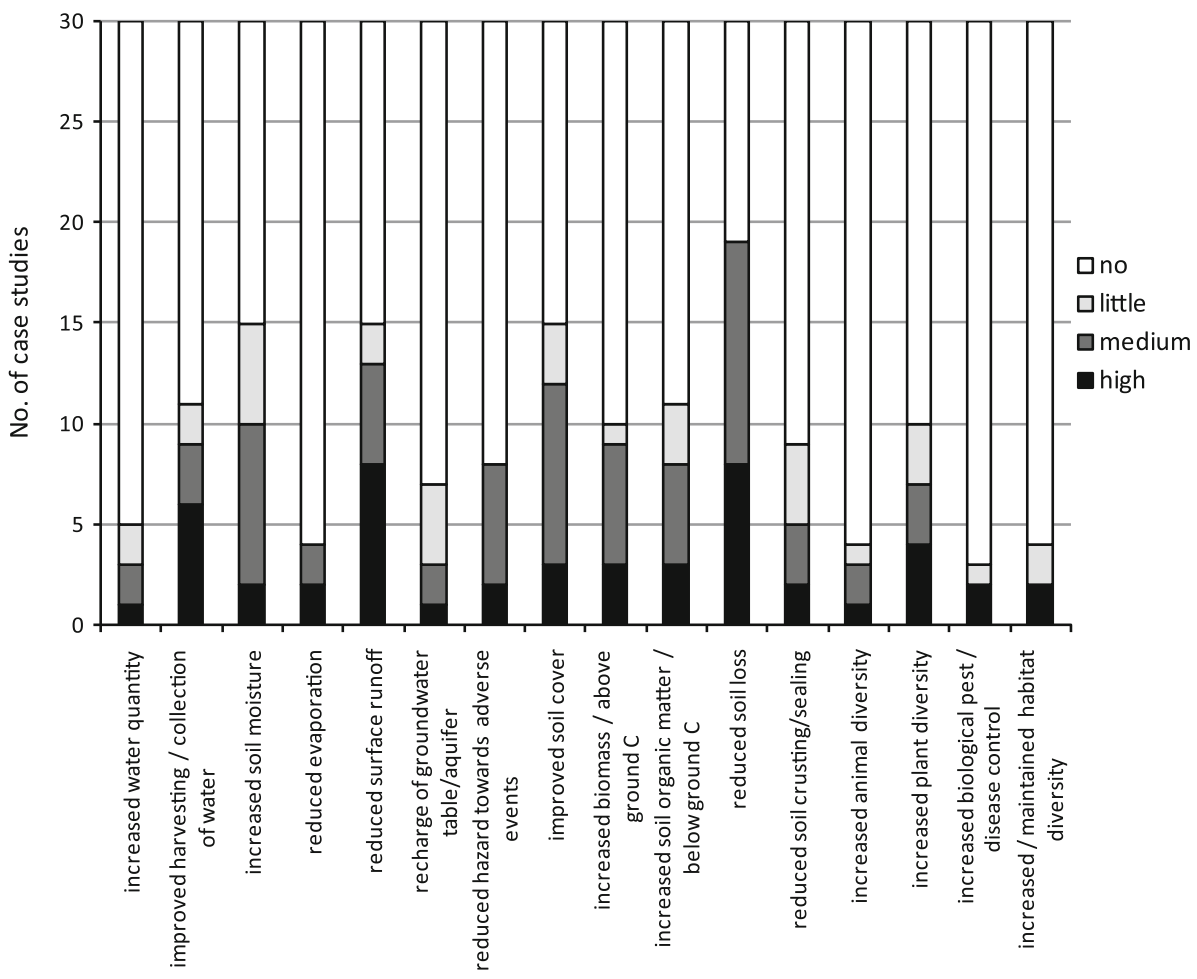

assess whether the productive flow of water is maximized, while unproductive water loss is minimized. GWUE is expressed as the fraction of plant transpiration (T) over precipitation (P) (Stroosnijder 2003, 2009). Unproductive water losses include soil evaporation, runoff, and percolation beyond the root zone. To analyze the GWUE of the documented technologies, the following impact indicators were considered: improved soil cover, reduced soil evaporation, increased soil moisture, and reduced surface runoff.
It was assumed that technologies showing the highest combined benefit across all indicators would improve GWUE best. The values assigned by the case study authors to these impacts were therefore added together for each technology individually. A total combined value of four or more was considered as a measurable improvement, since the impact was high and/or affected more than one indicator. Figure 3 shows that 14 technologies appeared to produce measurable improvements. Four technologies showed 
no impact for any of the indicators. Cropping management and cross-slope barriers were most effective in increasing GWUE. This is due to their high impact in improving soil moisture through in situ water conservation. Under dryland conditions, this usually leads to increased yields. Surface runoff-a key cause of water loss-was most effectively reduced by improved cropping management and crossslope barriers. The recharge of the groundwater table/ aquifer was mainly an issue for the water management technologies: a small to medium increase was assessed in connection with four technologies in Greece (GRE05), Spain (SPA04), and Tunisia (TUN09, TUN12), while a high increase was reported regarding the recharge well in Tunisia (being the specific target of that SLM practice). In Nestos, Greece, where salinization of irrigation water (not water quantity) is the biggest problem, improved water quality and reduced salinity were reported impacts of the applied water management technology (transport of freshwater from local streams).

Half of the case studies reported improved soil covertypically $20-50 \%$ improvement-by means of crops, fodder, weeds, shrubs, or dead material. Though an increase in production was reported in connection with the water management technologies, it apparently did not correspond to an increase in soil cover (level or duration). With only half of the technologies documented in DESIRE reporting improved soil cover, it remains to be explored whether the current understanding of dryland SLM-which puts great emphasis on improving soil cover-should correspondingly be adjusted. Some argue that improved soil cover reduces runoff and evaporation, leaving a greater share of the rainfall for green biomass and enabling a "greening of the land" without compromising (crop) production (Stroosnijder 2009). However, improved vegetative soil cover may compete with crops for both water and nutrients. And improving soil cover through dead material, such as mulch, may be complicated by fodder requirements or wind. In addition, farmers may fear pests and diseases caused by use of mulch (Moroccan farmers, oral communication).

Though the greatest water-related impacts were achieved by relatively few technologies, it should be noted that every technology, save one (prescribed fire from Portugal), displayed some sort of positive impact on water, as detailed above.

\section{Reduced Soil Degradation}

While the majority of reported benefits were expected to relate to water, more benefits were reported regarding soil loss. Eighteen technologies reportedly reduced soil loss: ten moderately (20-50\%) and eight highly (>50\%). However, due to their professional background, there may have been a tendency among the case study authors to focus on soil erosion rather than other issues. For many years and in numerous implementation and research projects, soil erosion was considered to be the main issue that needed to be addressed by SWC efforts. Though SLM's focus has since been broadened, soil erosion continues to be emphasized. Even sites that had not initially identified it as a problem reported reduced soil loss, especially in connection with grazing and cropping management technologies (see Fig. 4). These mainly concern the examples of crop rotation and less so the no- or minimum-tillage technologies. Two technologies did not appear to reduce soil loss, even though soil erosion was indicated as a target problem prior to their application. This concerns "gully control by plantation of Atriplex" (Morocco) and "woven wood fences" in Turkey. These were installed only very
Fig. 3 Aggregated impacts of SLM technologies in regards to GWUE

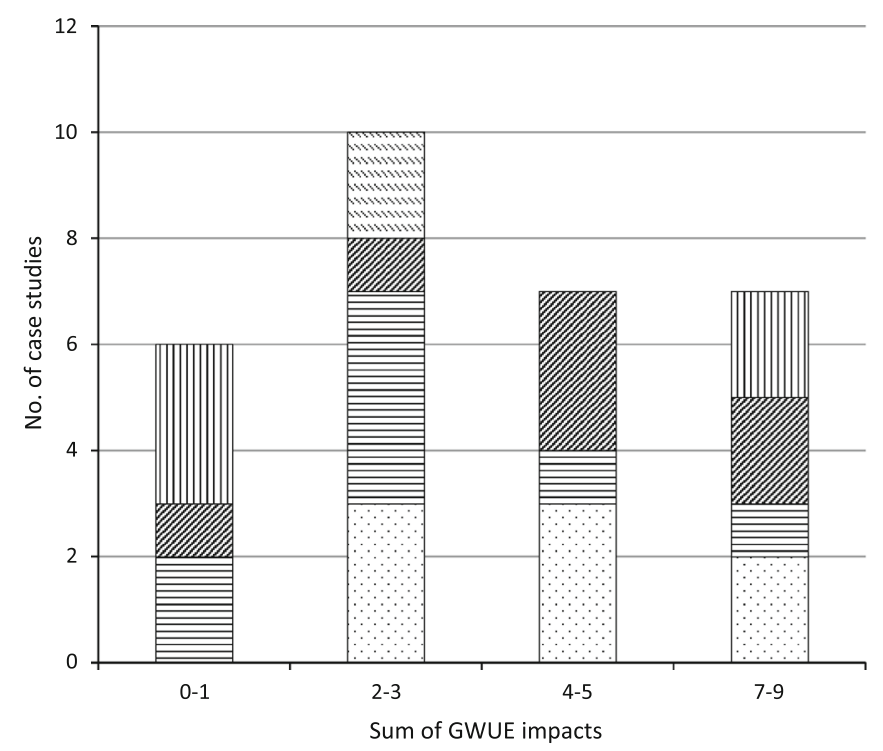

Impacts considered:

- improved soil cover

- reduced soil evaporation

- increased soil moisture

- reduced surface runoff

Impact values:

$1=$ little (5-20\%);

$2=$ medium $(20-50 \%)$;

$3=$ high $(>50 \%)$

$\square$ Forest management

区 Grazing land management

ZCross-slope barriers

$\equiv$ Water management

$\ulcorner$ Cropping management 


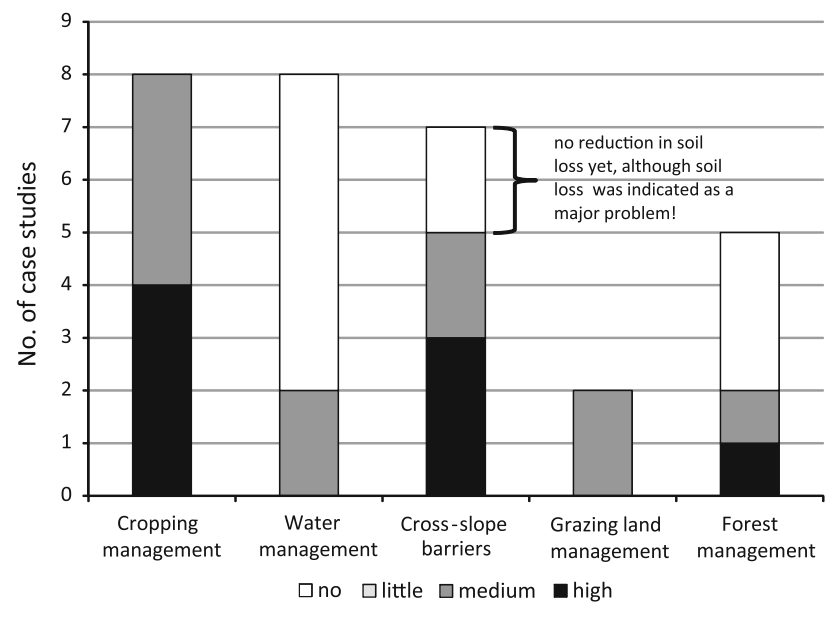

Fig. 4 Reduction of soil loss

recently and it will take some time for measurable reductions in soil loss to occur.

Most of the technologies that were applied to soils with low-organic matter content apparently had difficulty improving soil organic matter. This could be due to the long time required to observe an increase in soil organic matter in dryland conditions, to difficulties measuring such changes, or to lack of data. Exceptions were those cropping management technologies that directly aimed to improve soil organic matter. Application of fertilizer is one possible solution for fertility decline: five of the eight cropping management technologies include application of fertilizer. Some of them use organic fertilizer from animal manure; others only apply phosphorus because nitrogen is made available with leguminous fallow cropping.

\section{Diversified and Enhanced Production}

Given the bio-physical and socio-economic constraints discussed earlier, production is usually rather low in drylands. Nevertheless, the potential to increase production is great, and areas with very low yields sometimes record the highest gains (Molden and others 2010). As seen in Fig. 5, improved production was reported in connection with nearly all of the technologies. This crucially indicates that SLM technologies are generally capable of increasing production and may be used to address increasing demands for food, fodder, and other products. Depending on the land use type, increases were experienced in crop yields, fodder or animal production (e.g., meat, milk), or wood production. Cross-slope barriers appeared to have the highest production benefit. Still, for each group, there were one or two technologies that showed no production benefit, such as the two no-tillage technologies used in olive (and almond) orchards in Spain and Greece. Their benefit relates more to reductions in costs and environmental damage rather than improved production, and a net increase in farm income is still achieved. Other technologies were not assessed regarding agricultural production benefits (e.g., the biogas example). One-third of the documented technologies - mainly those in the water management groupreduced the risk of production failure.

The extent to this production improvement also raises land users' income depends on the inputs (expenditures) required to apply the technology. Increased incomes due to improved land management were reported in three-quarters of the cases of applied technologies, excluding forest management technologies, for which such analysis is not applicable. Though nine technologies increased land users' expenditures on agricultural inputs-mainly in the cropping management group due to investments in special machinery (e.g., no-tillage) or in seeds (e.g., legumes) increases in net farm income were still reported.

Diversification of income sources was a reported benefit of five technologies, though only "land reclamation with agave forestry" in Mexico registered a high impact due to new alcohol production. Diversification of agricultural products was also reported in connection with certain technologies.

\section{Socio-Cultural Benefits Including Conflict Mitigation} and Prevention of Outmigration

The most frequently reported socio-cultural benefit was "improved conservation/erosion knowledge." Stakeholders appeared to highly value the knowledge they gained by implementing SLM technologies (reported in $80 \%$ of the cases). Such knowledge gains typically facilitate further investment in SLM (de Graaff and others 2008).

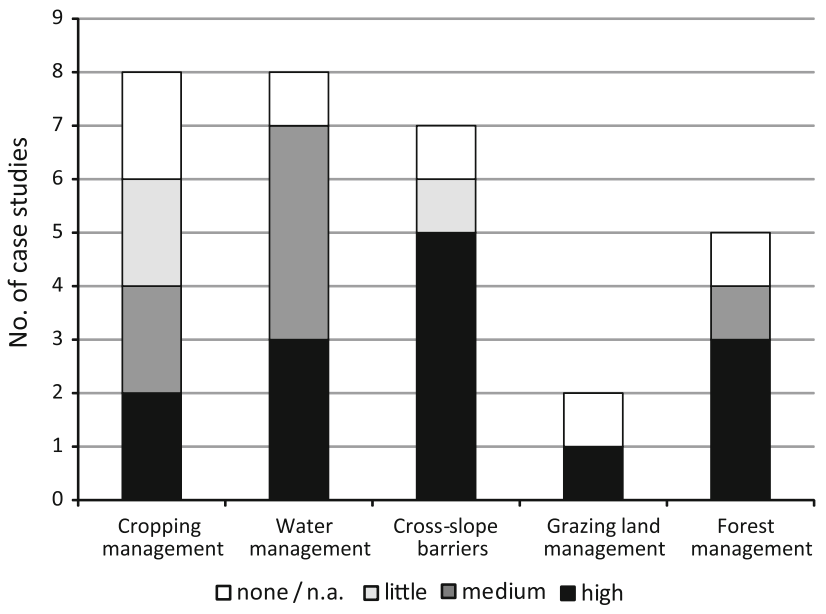

Fig. 5 Increase in production (crop yield, fodder, animal and wood) across the SLM technology groups 
Another benefit is strengthening of community or national institutions, as reported in connection with forest management technologies, where it appears key.

Whether or not the technologies contributed to improved livelihoods and human well-being was also assessed. Remarkably, a positive impact was reported for every technology, without exception, in this regard. More than half of the technologies reportedly had a medium or high impact (selected from the qualitative response options "no", "little", "moderate", and "high"), mainly by increasing people's incomes. Other relevant improvements related to water availability, diversification of food, reduced damage to fields and infrastructure, reduced outmigration, reduced workloads, increased energy, provision of medicinal plants, and reduced risk of wildfires.

Conflict mitigation was reported for seven technologies spread between all the groups, except cropping management. On the other hand, four of the five forest management technologies appeared to increase socio-cultural conflicts, though only slightly. The reasons were manifold, but had to do with restrictions on land use for certain periods or for certain users. For land reclamation with agave forestry, a high increase in conflicts was expected due to the high economic benefits of alcohol production as well as potential alcohol abuse within land users' families.

Outmigration reduction, identified in four sites as a criterion for selecting the SLM technology for test implementation (Schwilch and others 2012a), was ultimately achieved by two technologies. In Mexico, the technology of land reclamation with agave forestry was found to generate very high incomes, and this "enables farmers" sons to remain in the community and work in the fields"; and in Tunisia, rangeland resting was found to "[combat] rural exodus and [increase] income from agriculture by $20 \%$ " by improving fodder and animal production/quality.

\section{Resilience to Climate Change and Variability}

Most of the technologies appear capable of tolerating expected climatic variations. In some areas, rainwater availability may actually increase in the future. But in the Mediterranean region, where the majority of the selected case studies are located, most climate prediction scenarios forecast declining rainfalls (EEA 2008).

All of the documented cropping management technologies are considered sensitive to droughts and dry spells. As they often concern annual crops grown with the bare minimum of rain, they are prone to crop failures with even a slight decrease in rainfall. Temporal variability, including periods of drought or delayed starts to the rainy season, can also affect crop growth. Further, these technologies do not enable alternative sources of income, in contrast to agroforestry systems, for example. On the other hand, the SLM technologies that improve soil water may reduce drought sensitivity. About one-third of the technologies (11 out of 30) are reportedly sensitive to seasonal decreases in rainfall. Water management technologies are especially sensitive to floods, as indicated for six of the eight technologies in this group. The challenge for these technologies is designing structures that are strong enough to withstand the power of floods. A reported $83 \%$ of the technologies are capable of tolerating extreme events such as storms: the cross-slope barriers, in particular, are designed to cope with such threats. This indicates that good SLM practices are already capable of coping with climatic extremes and potential shifts.

\section{Cost-Benefit Analysis of the SLM Technologies}

The costs of SLM technologies are often difficult to assess. Distinguishing normal agricultural inputs from the additional expenses of the SLM technology can be a challenge. Low-cost technologies (below $100 \mathrm{USD} / \mathrm{ha})^{4}$ are mostly found in the groups of cropping management and grazing land management - though their maintenance costs can be considerable. The water management technologies are the most expensive (2,000-10,000 USD/ha), but this group also bears the highest potential to increase profits, making the investments very worthwhile. Maintenance costs are usually rather low, i.e., less than $300 \mathrm{USD} / \mathrm{ha} / \mathrm{year}$. Costs often restrict poor land users from implementing technologies, even if the investment would pay off in the long run. Subsidies enable them to avoid paying the full cost of establishment or maintenance. Among the studied cases, land users typically either paid almost all the costs of establishment (11 cases with contributions of 90-100\%) or almost nothing (9 cases with contributions of 0-10\%)-the latter where project funds or the government provided subsidies. However, more than half of the technologies documented were fully maintained at the land users' expense. As with any investment, the benefits must be weighed as well; the costs should not be considered in isolation.

Demonstrating a favorable local-scale cost-benefit relationship is central to the adoption and spread of SLM. This requires accurate assessment of SLM interventions' monetary and non-monetary costs and benefits. Not everyone perceives non-economic costs and benefits the same way. The WOCAT questionnaires could only capture the subjective qualitative assessment of the DESIRE case study authors. For most technologies, the long-term relationship between benefits and costs (of any type) appears to range from positive to very positive, as presented in Fig. 6. However, the picture is different regarding short-term

\footnotetext{
4 For certain technologies, costs are indicated per unit rather than per hectare, but in all cases this was comparable to a hectare (e.g., the recharge well in Tunisia benefits one hectare of irrigation land).
} 
benefits, which appear to be outweighed by establishment costs for many technologies, in particular those in the water management, cross-slope barrier, and forest management groups (see Fig. 7). One possible conclusion is that implementation of most SLM technologies will produce negative returns on investment for the first three years, and that land users will require support from revolving funds, payment for ecosystem services, or other financial mechanisms in order to obtain the economic value of SLM technologies in the long term (5-10 years).

Further, cost-benefit calculations should not focus only on local land users, but also on the wider society and economy. This requires examination of the off-site benefits of SLM technologies. Half of the technologies documented in the DESIRE case studies provide off-site benefits, such as reduced damage to neighbors' fields and public/private infrastructure, or reduced downstream flooding. Many of the technologies are situated in mountainous areas and play an important role in regulating water provision for downstream users. More difficult to assess are the contributions of SLM to mitigating climate change (e.g., through carbon sequestration), preventing disasters and environmental threats (e.g., mud flows, flooding), or reducing vulnerability to economic crises.

Inputs and achievements also very much depend on the stage of degradation at which SLM interventions are attempted. The best input-benefit ratio will normally be achieved by measures of prevention, followed by those of mitigation, and finally rehabilitation measures (WOCAT 2007). The DESIRE case studies confirm this finding: the technologies aimed at rehabilitation display a lower costbenefit ratio than those aimed at prevention or mitigation. This implies that while the impacts of rehabilitation efforts may be highly visible, their achievements must be critically considered in terms of costs. Of the 30 technologies analyzed, only 5 were described as aimed at rehabilitation; these mainly concerned recovering the lost productivity of highly degraded forest or grazing land by planting highvalue trees and shrubs or producing biogas to reduce the pressure on fuelwood.
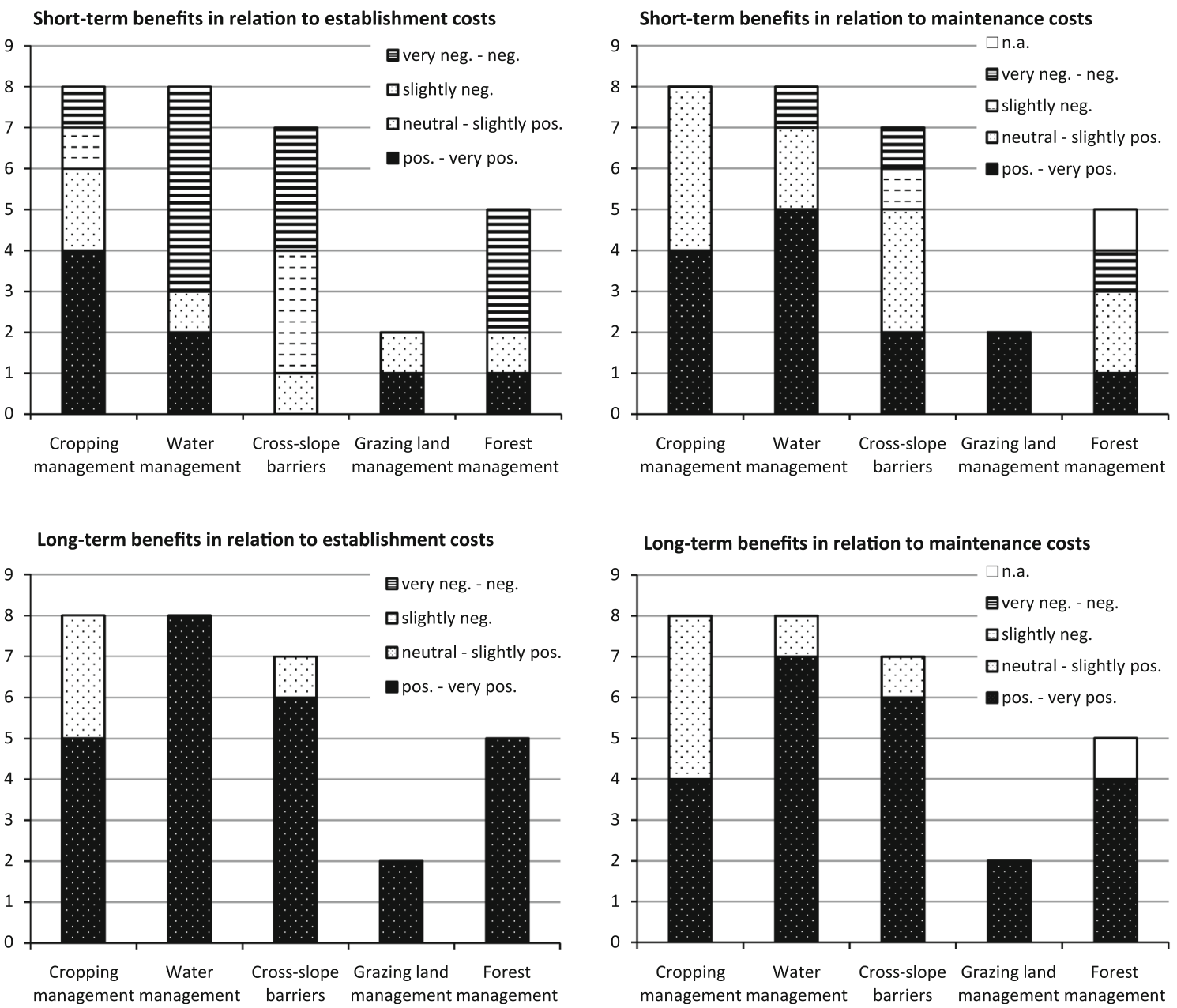

Fig. 6 Perceived benefits of SLM technologies in the short term and the long term in relation to establishment and maintenance costs 
Fig. 7 Establishment costs in USD/ha compared with shortterm cost-benefit ratio

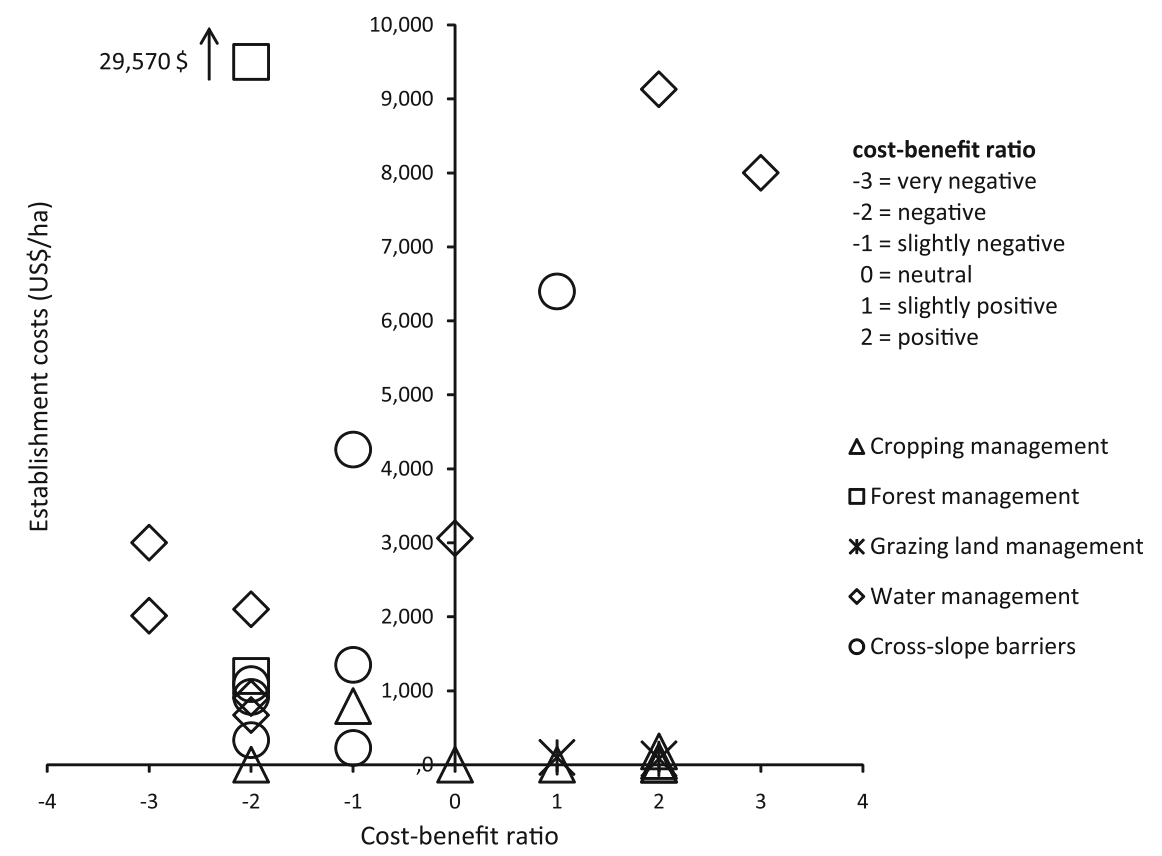

Key Impacts of Dryland SLM Approaches

In more than half of the DESIRE case studies, the local community was actively involved in all stages of the approach, as seen in Fig. 8. However, analysis of the DESIRE case studies reveals that most SLM interventions were driven by experts. Only in Mexico and Tunisia was the decision a joint one made by various stakeholders. Moderate to substantial differences in the level of participation of men versus women were reported in most case studies. Men typically perform the hard manual labor in the field and during implementation of SLM measures, while women are more responsible for work in and around the house. Portugal and Russia were the only sites where no gender difference was identified. Remarkably, $40 \%$ of the documented households in Cape Verde were headed by women, mainly due to their husbands' migration to other areas or countries.

Training, advisory services, and research are other key elements of SLM approaches. Training was provided in all eight documented approaches, primarily to land users and field staff/agricultural advisors. Training was provided in the form of public meetings, information sessions, site visits, demonstration areas, on-the-job experience, and farmer-to-farmer exchange. The effectiveness of training and extension services was considered good to excellent in most cases, except in Spain. Apparently, there is a substantial lack of training for land users in Spain. The case study authors write that the extension system there is currently strongly focused on control rather than on advice and training activities. More information and awarenessbuilding efforts are required on behalf of land users, as such information is often only available at the political or research level.

Besides improving the sustainable management of land, most approaches were found to contribute to improved livelihoods, decreased poverty, and improved situations for socially and economically disadvantaged groups. The use of subsidies and their long-term impact on the implementation of SLM was not considered as a problem anywhere. On the contrary, in six approaches, the impact of subsidies

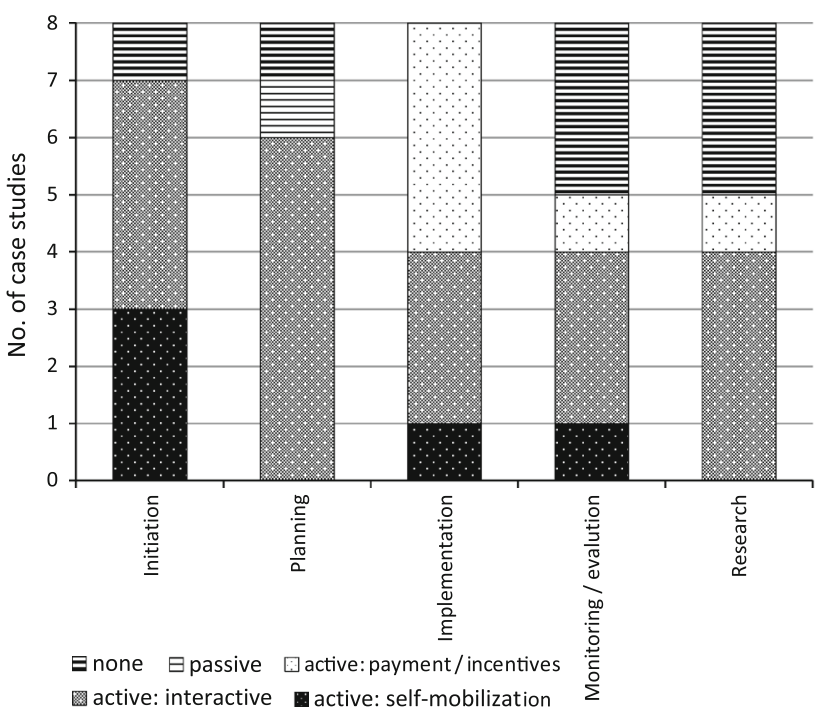

Fig. 8 Community involvement in different stages of the SLM approach. Beside "none" and "passive" involvement, three different types of "active" involvement are distinguished: active involvement through payment or other incentives, interactive involvement by participation, and self-mobilization of communities (WOCAT 2008b) 
was considered positive. Only in the Tunisia case study was a decrease in people's willingness to invest in SLM technologies reported when financial support was not provided, as land users had come to rely on being paid for each area treated. Nevertheless, in the Tunisia case and elsewhere (Chile and Spain), it remains uncertain whether land users could continue the SLM approach without support. Indeed, none of the eight SLM approaches studied appears fully capable of generating a self-supporting, market-driven mechanism that will guarantee its continuation. This suggests that financial mechanisms are required to support the starting phase of SLM approaches and possibly subsequent phases. Again, such mechanisms could include subsidies, revolving funds, contracts, or payment for ecosystem services.

\section{Discussion}

\section{Desertification Mitigation}

The analyses presented here demonstrate how the documented SLM technologies and their implementation approaches are addressing desertification threats. Table 3 summarizes the key findings, listing the identified threats, the benefits of given DESIRE SLM technologies, and assessments of their impact. Technically, the assessed SLM practices in drylands mainly function by means of controlling runoff and erosion as well as improving ground cover and soil moisture. These mechanisms complement each other and may be considered key functions of SLM technologies in drylands. The generalized overview in Table 3 shows that all the groups are successfully tackling the desertification threats, with no group setting itself apart from the others in terms of performance. This suggests that there are no universal "best practices," not even in a global subset such as drylands (Bayala and others 2012).

Comparing the list of documented SLM technologies with similar assessments elsewhere (WOCAT 2007; Liniger and others 2011), it is striking that the group of soil fertility management technologies appears to be missing. The data analyzed here appear to contradict the finding from other dryland research, mainly from sub-Saharan Africa (Stroosnijder 2003), that efficient water management is impossible without improved nutrient management. In the documented case studies, (reduced) soil fertility apparently did not constrain production or may have been compensated for with fertilizer, as applied in many of the cropping management technologies. However, other than the nitrogen-fixing leguminous crop rotation/green manure systems, no technologies were applied which specifically sought to improve soil fertility and the nutrient cycle.
Table 3 Desertification threats tackled by SLM technologies in the DESIRE project

\begin{tabular}{|c|c|c|}
\hline $\begin{array}{l}\text { Desertification } \\
\text { threat }\end{array}$ & Related SLM benefits & $\begin{array}{l}\text { Impact achieved by } \\
\text { DESIRE SLM } \\
\text { technologies }\end{array}$ \\
\hline Water scarcity & $\begin{array}{l}\text { Improved water } \\
\text { management through } \\
\text { increased water } \\
\text { quantity, reduced water } \\
\text { loss through runoff and } \\
\text { evaporation, improved } \\
\text { soil moisture, improved } \\
\text { water harvesting, } \\
\text { recharge of } \\
\text { groundwater }\end{array}$ & $\begin{array}{l}\text { High impact, mainly } \\
\text { through water } \\
\text { management, } \\
\text { cropping } \\
\text { management, and } \\
\text { cross-slope barriers }\end{array}$ \\
\hline Soil degradation & $\begin{array}{l}\text { Reduced soil loss, } \\
\text { reduced crusting and } \\
\text { sealing, reduced } \\
\text { damage on neighbors' } \\
\text { fields and public/private } \\
\text { infrastructure }\end{array}$ & $\begin{array}{l}\text { Very high impact, } \\
\text { mainly through } \\
\text { cropping } \\
\text { management and } \\
\text { cross-slope barriers, } \\
\text { but also through } \\
\text { forest and grazing } \\
\text { management }\end{array}$ \\
\hline $\begin{array}{l}\text { Vegetation } \\
\text { degradation } \\
\text { and low } \\
\text { production }\end{array}$ & $\begin{array}{l}\text { Improved soil cover, } \\
\text { improved biomass, } \\
\text { diversified and } \\
\text { enhanced production, } \\
\text { improved water use } \\
\text { efficiency, improved } \\
\text { soil organic matter, } \\
\text { improved pest and } \\
\text { disease control, reduced } \\
\text { risk of production } \\
\text { failure, increased farm } \\
\text { income }\end{array}$ & $\begin{array}{l}\text { Medium to high } \\
\text { impact by all } \\
\text { technology groups; } \\
\text { water management } \\
\text { shows smallest } \\
\text { impact }\end{array}$ \\
\hline Climate change & $\begin{array}{l}\text { Resilience toward climate } \\
\text { change and variability } \\
\text { through reduced } \\
\text { vulnerability toward } \\
\text { adverse events, reduced } \\
\text { risk of production } \\
\text { failure, reduced } \\
\text { downstream flooding, } \\
\text { diversification of } \\
\text { income sources }\end{array}$ & $\begin{array}{l}\text { Medium impact, } \\
\text { mainly through } \\
\text { water management } \\
\text { and cross-slope } \\
\text { barriers. Sensitivity } \\
\text { of cropping } \\
\text { management to } \\
\text { droughts and water } \\
\text { management to } \\
\text { floods. }\end{array}$ \\
\hline $\begin{array}{l}\text { Resource use } \\
\text { conflicts, } \\
\text { migration }\end{array}$ & $\begin{array}{l}\text { Socio-cultural benefits } \\
\text { including conflict } \\
\text { mitigation, prevention } \\
\text { of outmigration, } \\
\text { institution } \\
\text { strengthening, } \\
\text { improved knowledge of } \\
\text { conservation/erosion }\end{array}$ & $\begin{array}{l}\text { Medium to high } \\
\text { impact on improved } \\
\text { livelihoods and } \\
\text { knowledge through } \\
\text { all technology } \\
\text { groups; some impact } \\
\text { on conflicts and } \\
\text { migration by most } \\
\text { technology groups }\end{array}$ \\
\hline
\end{tabular}

The principles of SLM elaborated by Liniger and others (2011) in the TerrAfrica initiative were only partly confirmed by the present data. Below, the principles and some of their indicators (in italics) are used to evaluate the DESIRE data: 
1. Improving water productivity: this was mostly achieved by reducing water loss through reduced surface runoff (15 technologies, mainly cropping management and cross-slope barriers). Water harvesting was achieved by five water management technologies specifically aimed at this, of which two were also successfully maximizing water storage and another was managing excess water (Tunisia recharge well).

2. Improving soil fertility and the nutrient cycle: here too, the greatest impact was reported in connection with cropping management technologies and crossslope barriers. Some aspects, such as cover and soil organic matter improvement, were also addressed by grazing and forest management technologies. Application of manure and compost was very rare (two cases only), while crop rotation, fallow and intercropping was reported six times. Trapping sediments and nutrients was exclusively found in connection with cross-slope barriers. The water management technologies hardly enhanced soil fertility except through some reduction of nutrient losses thanks to improved irrigation.

3. Improving planting material and plant management: the four crop rotation case studies (mixed plant systems, selection of seeds) were most successful in this area. Weed management was key to the four no- or reduced-tillage technologies. Two of the forest management examples and one of the cross-slope barriers also benefitted from synergies between different plants. No benefits were reported for water management technologies with respect to this principle.

4. Creating a favorable micro-climate: as this principle mostly relates to improved cover, it was not assessed separately.

Overall, the cropping management technologies and the cross-slope barriers appear best at addressing the first three principles, while the water management technologies are mainly focused on improving water availability.

One possible criticism of the above principles is that they are too focused on cropland. The two forest fire prevention technologies, for example, do not appear to have any place among the principles. Technologies related to alternative energy sources (such as biogas) also do not seem to fit. Thus, the addition of two more principles is recommended:

5. Protecting against extreme events and shifts: fire prevention, diversification of production, permanent cover, adjusting agricultural and ecological systems within a landscape, etc.

6. Reducing pressure on resources by providing alternatives: biogas rather than fuelwood, energy saving stoves, etc.
In addition to these separate, mainly environmental principles, SLM should aim at improving people's livelihoods and overall ecosystems in order to address all the dimensions of sustainability. Liniger and others (2011) highlight the importance of supportive institutions, policy, governance, economic measures, knowledge management, and capacity building. It should also be noted that sustainability is a normative concept that varies over time and space (Pohl and others 2010). SLM priorities should be determined according to stakeholders' objectives, especially those of land users, in order to achieve maximum benefits (Nkonya and others 2011) — which should not be equated with maximum profits. Due to the heightened risk of production failure in drylands, land users in these areas may be reluctant to test new SLM technologies, unless ways are found to reduce their risk and generate short-term benefits.

In combination with the principles summarized above, the real-world SLM experiences documented in the WOCAT database enable users to make informed decisions about the applicability and likely performance of specific SLM options hitherto untested in their region. The WOCAT database provides search criteria based on standardized assessments of individual technologies and approaches. These same search criteria may be used as parameters for extrapolation. Documented SLM practices that have performed well in a given region according to selected criteria may be upscaled within the same region or tested elsewhere. The same indicators are used to facilitate selection of suitable SLM options and support decision-making regarding testing them in any given area (Schwilch and others 2012a). Nevertheless, expanding local SLM practices in order to achieve largerscale impacts remains a major challenge. Doing so requires creation of an enabling environment at the envisioned scale (Kessler and Stroosnijder 2010; Akhtar-Schuster and others 2011), in addition to collective action at the local level.

\section{WOCAT Assessment}

What is the added value of evaluating and documenting SLM technologies and approaches with the WOCAT tools? While using the WOCAT tools to document and evaluate may be demanding, the DESIRE project showed how doing so enriches the experience of users, that is, the experts and land users who supply the information. A DESIRE study site researcher described it as follows: "The questionnaires force the user to go through all aspects/issues and to talk to numerous people (land users, administrators)." The process enables gaining new insights into applied technologies and approaches and serves as a tool for self-evaluation. The knowledge gained on degradation and conservation is great and facilitates further investments in SLM. This confirms the need for and the benefit of the WOCAT methodology. 
Further, the documented case studies are simultaneously made available worldwide by means of a shared, online database.

Nevertheless, the DESIRE data review process revealed some clear bottlenecks, echoing the findings of an earlier evaluation (Liniger and others 2004). For example, the information provided by the case study authors is often unclear and not sufficiently complete to be understood by an external readership. There are also gaps and inconsistencies in the information provided that must be sorted out in an interactive way, comprising several review-improvement cycles. Considerable effort is required to enhance the quality of the documentation, including language editing, the addition of high-quality photos and drawings as well as improved explanation of facts that might be self-evident to local readers but not to an international audience. Further, it is generally very difficult to quantify the costs and benefits of SLM technologies and approaches. Usually, WOCAT assesses costs of technology implementation that are additional to ordinary field operations, but when the field operations are partly the same as the technology (as in Conservation Agriculture), all activities should individually be considered and compared, making assessment especially complex and difficult. Further, while it is very important to calculate the direct costs or financial benefits of SLM technologies to land users, other factors are crucial to the decision of whether to adopt SLM (de Graaff and others 2008; Schneider and others 2010). One must consider the combined economic, social-cultural, and ecological benefits, accounting for trade-offs as well as off-site effects.

Overall, analysis of data obtained with the WOCAT questionnaires enables field-level observations from different sites to be pulled together and systematically compared. This article has sought to analyze a specific subset of the WOCAT database- the DESIRE SLM technologies and approaches-in a scientific way. This has posed some challenges and revealed some limitations. Identification and assessment of SLM impacts was the primary aim; however, a major limitation of the WOCAT methodology was observed in this area: the WOCAT questionnaire suggests a list of potential SLM impacts that may individually be selected, complemented, and assessed by users and the case study authors. However, this means that only those impacts that are selected by multiple authors may be compared across technologies. Further, even if an impact was not selected, it may still have occurred. It may not have been selected simply because it did not seem important to the author, did not appear relevant in the context, or was not assessed and remains unaccounted for. For example, if several technologies-including a forest management technology—are compared regarding their impact on soil moisture, the forest management technology may not show an impact simply because it was not relevant and was therefore not assessed. Further, many SLM impacts are interrelated, such as increased water quantity and improved harvesting of water, or improved soil cover and reduced soil evaporation. It then depends on the perspective of the case study authors if one or the other or both are indicated, which again has a diluting effect on the comparison of technologies.

Indeed, the perspective and perception of the case study authors are prevalent throughout the documentation, especially regarding the impact assessment. The results can markedly be subjective in this area, particularly if no quantitative data are available. In the DESIRE project, a tendency to stress bio-physical impacts such as soil erosion was found, likely due to the professional background of the case study authors. Further, there is a risk that the case study authors may overestimate desired impacts and ignore negative impacts. This latter effect may be minimized by including stakeholder perspectives, namely the opinion of land users. Thus, the WOCAT methodology specifically encourages SLM specialists to question their own understanding and consult with land users when documenting SLM experiences. In addition, case studies are usually assessed and documented by a team of experts in order to arrive at a reliable overall assessment and to ensure that the opinions of one expert do not dominate. Ideally, these teams of SLM specialists or researchers will be interdisciplinary, so as to include bio-physical, social, and economic analyses.

Despite the difficulty of analyzing data compiled with the WOCAT questionnaire in a scientifically robust way, the breadth and comprehensiveness of WOCAT's SLM assessments exceed similar efforts. SLM assessments by others either focus solely on a specific technology group (Biazin and others 2012; Giller and others 2009; Rockström and others 2009), bio-physical aspects (Sahrawat and others 2010; Ward and others 2012), or economic productivity (Bayala and others 2012; Farooq and others 2011). Still others compare whole farming systems-for example, dairy farms versus arable farms (van Passel and Meul 2012) - necessitating adoption of an entirely different system, something many farmers will reject.

Requiring the case study authors to provide more quantitative data, especially regarding impact assessment, could further enhance the usefulness of the holistic information compiled using the WOCAT questionnaires. More research is needed to reinforce their expert valuations of SLM impacts (e.g., by developing standardized, simple, and cost-effective field assessment methods) and provide the necessary evidence-based rationale for investing in SLM. Some of the other limitations identified can be minimized by hiring a team of reviewers to ensure the 
quality of the data, looking for inconsistencies and contradictions.

\section{Conclusions}

Stakeholders and researchers at the DESIRE study sites considered application of the WOCAT methodology within the DESIRE project valuable, and its use in the project also greatly benefitted the global WOCAT database. Case studies from hitherto underrepresented regions (such as the Mediterranean) and important degradation problems (such as forest fires) have been made available to a global audience. This important set of dryland SLM experiences has enriched the WOCAT database with information from diverse societal and economic contexts, including former socialist societies (China, Russia) and those subject to current European market regulation regimes. Further, the documentation confirmed the lack of SLM knowledge and experience from rangeland areas, which are very widespread in drylands. Finally, analysis of the SLM technologies confirmed that more field research is needed to reinforce expert assessments of SLM impacts and provide the necessary motivation and rationale for investment in SLM.

This article has identified several key aspects of successful SLM technologies and approaches in drylands. It has enabled initial evaluation of how SLM addresses prevalent dryland threats, such as water scarcity, soil degradation, vegetation degradation and low production, climate change, resource use conflicts, and migration. It confirms, in part, the proposed solutions to land and water degradation presented by Bossio and others (2010), including focusing on smallholder agriculture and resource-conserving practices as well as enhancing the multi-functionality of agricultural landscapes. Indeed, most SLM technologies are applied by small-scale land users, a group that is often underestimated regarding their investment and innovation as well as their role in worldwide agricultural production (IAASTD 2008; Wegner and Zwart 2011). Further, somebut not all-of the SLM principles presented in earlier WOCAT publications were confirmed by the present analyses.

One of the aims of the DESIRE project is to upscale field-tested SLM technologies and approaches to cover a larger area than the original study site, for example an entire country. A modeling approach was developed to evaluate the likely environmental effects of adopting different SLM strategies at different scales (e.g., regionally); the modeling approach also serves to assess financial viability (Fleskens and others this issue). This research supplied the basic data used in this new combination of biophysical and socio-economic modeling. The results were fed into regional- and/or national-level policymaking. Finally, this research enabled comparison of different SLM options and shared learning across different sites and different countries.

Acknowledgments This study was conducted within the framework of the EC-DG RTD, 6th Framework Research Programme (sub-priority 1.1.6.3), Research on Desertification, project DESIRE (037046): Desertification Mitigation and Remediation of Land-a global approach for local solutions. The authors extend their deep thanks to all the contributors of DESIRE case studies, namely J. Al Karkouri, J. Atlhopheng, M. Ben Zaied, L. Borselli, M. Carreiras, M. Chaker, M. Chniter, C. Coelho, J. de Vente, S. Espinoza, A. Ferreira, I. Gkiougkis, C. Kosmas, A. Laouina, N. Machouri, N. Mahdhi, A. Martínez Palacios, R. Nafaa, P. Palheiro, E.R. Patrón, C. Prat, F. Ocakoğlu, M. Ouessar, A. Oueled Belgacem, C. Ovalle, R. Sebego, M. Sghaier, J. Soares, A. Solé Benet, J. Tavares, İ. Tolay, S. Valente, Wang Fei, H. Yahyaoui, A. Zeiliguer, M. Zengin. Thanks also to C. De Maddalena and C. Hauser for their support in compiling the case studies, to A. Lannen for editing.

\section{References}

Akhtar-Schuster M, Thomas RJ, Stringer LC, Chasek P, Seely M (2011) Improving the enabling environment to combat land degradation: institutional, financial, legal and science-policy challenges and solutions. Land Degrad \& Dev 22(2):299-312. doi:10.1002/ldr.1058

Bayala J, Sileshi G, Coe R, Kalinganire A, Tchoundjeu Z, Sinclair F, Garrity D (2012) Cereal yield response to conservation agriculture practices in drylands of West Africa: a quantitative synthesis. J Arid Environ 78:13-25

Biazin B, Sterk G, Temesgen M, Abdulkedir A, Stroosnijder L (2012) Rainwater harvesting and management in rainfed agricultural systems in sub-Saharan Africa-a review. Phys and Chem of the Earth 47-48:139-151. doi:10.1016/j.pce.2011.08.015

Bossio D, Geheb K, Critchley W (2010) Managing water by managing land: addressing land degradation to improve water productivity and rural livelihoods. Agric Water Manag 97: 536-542

Cowie AL, Penman TD, Gorissen L, Winslow MD, Lehmann J, Tyrrell TD, Twomlow S, Wilkes A, Lal R, Jones JW, Paulsch A, Kellner K, Akhtar-Schuster M (2011) Towards sustainable land management in the drylands: scientific connections in monitoring and assessing dryland degradation, climate change and biodiversity. Land Degrad \& Dev 22(2):248-260

Critchley W, Cooke R, Jallow T, Lafleur S, Laman M, Njoroge J, Nyagah V, and E. Saint-Firmin (eds) (1999) Promoting Farmer Innovation. Harnessing Local Environmental Knowledge in East Africa. Report series 2. Regional Land Management Unit (RELMA) Workshop. Nairobi, Kenya. Regional Land Management Unit, RELMA/Sida, ICRAF House, Girigi

de Graaff J, Amsalu A, Bodnár F, Kessler A, Posthumus H, Tenge A (2008) Factors influencing adoption and continued use of longterm soil and water conservation measures in five developing countries. Appl Geogr 28:271-280

EEA (2008) Impacts of Europe's changing climate-2008 indicatorbased assessment. EEA Report No 4/2008

Farooq M, Flower K, Jabran K, Wahid A, Siddique K (2011) Crop yield and weed management in rainfed conservation agriculture. Soil and Tillage Res 117:172-183

Giller K, Witter E, Corbeels M, Tittonell P (2009) Conservation agriculture and smallholder farming in Africa: the heretics' view. Field Crops Res 114:23-34 
Hessel R, Reed M, Geeson N, Ritsema C, van Lynden G, Karavitis C, Schwilch G, Jetten V, Burger P, van de Werff ten Bosch MJB, Verzandvoort S, van den Elsen E, Witsenburg K (2013) From Framework to Action: The DESIRE approach to combat desertification (under revision)

Hurni H, Herweg K, Portner B, Liniger H (2008) Soil Erosion and Conservation in Global Agriculture. In: Braimoh AK, Vlek PLG (eds) Land use and soil res. Springer, New York, pp 41-71

IAASTD (2008) International assessment of agricultural knowledge. Science and Technology for Development, Washington

Jetten V et al (2013) Testing SWC methods in 16 countries, do best practices exist? (in preparation)

Kessler A, Stroosnijder L (2010) Debating land degradation: strategy development for Bolivian mountain valleys. Land Degrad \& Dev 21:480-483

Liniger HP, Douglas M, Schwilch G (2004) Towards sustainable land management-'Common sense' and some other key missing elements (the WOCAT experience). Proceedings of ISCO Conference 2004, Brisbane

Liniger HP, Mekdaschi Studer R, Hauert C, Gurtner M (2011) Sustainable Land Management in Practice-Guidelines and Best Practices for Sub-Saharan Africa. TerrAfrica, World Overview of Conservation Approaches and Technologies (WOCAT) and Food and Agriculture Organization of the United Nations (FAO)

MA (2005) Ecosystems and human well-being: desertification synthesis. Millennium ecosystem assessment. World Resources Institute, Washington

Molden D, Oweis T, Steduto P, Bindraban P, Hanjra M, Kijne J (2010) Improving agricultural water productivity: between optimism and caution. Agric Water Manag 97:528-535

Nkonya E, Winslow M, Reed M, Mortimore M, Mirzabaev A (2011) Monitoring and assessing the influence of social, economic and policy factors on sustainable land management in drylands. Land Degrad \& Dev 22:240-247

Pohl C, Rist S, Zimmermann A, Fry P, Gurung G, Schneider F, Speranza C, Kiteme B, Boillat S, Serrano E, Hadorn G, Wiesmann U (2010) Researchers' roles in knowledge coproduction: experience from sustainability research in Kenya, Switzerland, Bolivia and Nepal. Science and Public Policy 37:267-281

Rockström J, Kaumbutho P, Mwalley J, Nzabi A, Temesgen M, Mawenya L, Barron J, Mutua J, Damgaard-Larsen S (2009) Conservation farming strategies in East and Southern Africa: yields and rain water productivity from on-farm action research. Soil and Tillage Res 103:23-32

Sahrawat K, Wani S, Pathak P, Rego T (2010) Managing natural resources of watersheds in the semi-arid tropics for improved soil and water quality: a review. Agric Water Manag 97:375-381

Schneider F, Ledermann T, Fry P, Rist S (2010) Soil conservation in Swiss agriculture - approaching abstract and symbolic meanings in farmers' life-worlds. Land Use Policy 27:332-339

Schwilch G, Bachmann F, Liniger HP (2009) Appraising and selecting conservation measures to mitigate desertification and land degradation based on stakeholder participation and global best practices. Land Degrad \& Dev 20:308-326. doi: 10.1002/Ldr.920

Schwilch G, Bestelmeyer B, Bunning S, Critchley W, Herrick J, Kellner K, Liniger HP, Nachtergaele F, Ritsema CJ, Schuster B, Tabo R, van Lynden G, Winslow M (2011) Experiences in monitoring and assessment of sustainable land management. Land Degrad \& Dev 22(2):214-225. doi:10.1002/ldr.1040
Schwilch G, Bachmann F, de Graaff J (2012a) Decision support for selecting SLM technologies with stakeholders. Appl Geogr 34:86-98. doi:10.1016/j.apgeog.2011.11.002

Schwilch G, Bachmann F, Valente S, Coelho C, Moreira J, Laouina A, Chaker M, Aderghal A, Reed MS, Santos P (2012b) A structured multi-stakeholder learning process for sustainable land management. J Environ Manag 107:52-63. doi:10.1016/ j.jenvman.2012.04.023

Schwilch G, Hessel R, Verzandvoort S (2012c) Desire for greener land. Options for sustainable land management in drylands. University of Bern-CDE, Alterra-Wageningen UR, ISRICWorld Soil Information, CTA-Technical Centre for Agriculture and Rural Cooperation, Wageningen

Sietz D, Lüdeke M, Walther C (2011) Categorisation of typical vulnerability patterns in global drylands. Global Environ Change 21:431-440

Srinivasan V, Lambin E, Gorelick S, Thompson B, Rozelle S (2012) The nature and causes of the global water crisis: syndromes from a meta-analysis of coupled human-water studies. Water Resour Res 48:W10516. doi:10.1029/2011WR011087

Stroosnijder L (2003) Technologies for improving green water use efficiency in semi-arid Africa. In: Beukes B, de Villeirs M, Mkize S, Sally H, van Rensburg L (eds) Proceedings Water Conservation Technologies for Sustainable Dryland Agriculture in Sub-Saharan Africa. Symposium and Workshop, Bloemfontein, pp 92-102

Stroosnijder L (2009) Modifying land management in order to improve efficiency of rainwater use in the African highlands. Soil and Tillage Res 103:247-256

Thomas R (2008) Opportunities to reduce the vulnerability of dryland farmers in Central and West Asia and North Africa to climate change. Agric, Ecosyst \& Environ 126:36-45

UNCCD (2008) The 10-year strategic plan and framework to enhance the implementation of the Convention (2008-2018). ICCD/ COP(8)/16/Add.1. http://www.unced.int

van Passel S, Meul M (2012) Multilevel and multi-user sustainability assessment of farming systems. Environ Impact Assess Rev $32: 170-180$

Ward P, Flower K, Cordingley N, Weeks C, Micin S (2012) Soil water balance with cover crops and conservation agriculture in a Mediterranean climate. Field Crops Res 132:33-39

Wegner L, Zwart G (2011) Who will feed the world? The production challenge, Oxfam Research Report. Oxfam, London, p 66

WOCAT (2007) Where the land is greener-case studies and analysis of soil and water conservation initiatives worldwide. Liniger HP, Critchley W (eds) CTA, FAO, UNEP, CDE, Berne

WOCAT (2008a) Questionnaire on SLM Technologies (Basic). A Framework for the Evaluation of sustainable land management (revised). Liniger HP, Schwilch G, Gurtner M, Mekdaschi Studer R, Hauert C, van Lynden G, Critchley W (eds) Centre for Development and Environment, Institute of Geography, University of Berne, Berne

WOCAT (2008b) Questionnaire on SLM Approaches (Basic). A Framework for the Evaluation of sustainable land management (revised). Liniger HP, Schwilch G, Gurtner M, Mekdaschi Studer R, Hauert C, van Lynden G, Critchley W (eds) Centre for Development and Environment, Institute of Geography, University of Bern, Bern

WWAP (World Water Assessment Programme) (2012) The United Nations World Water Development Report 4: managing water under uncertainty and risk. UNESCO, Paris 